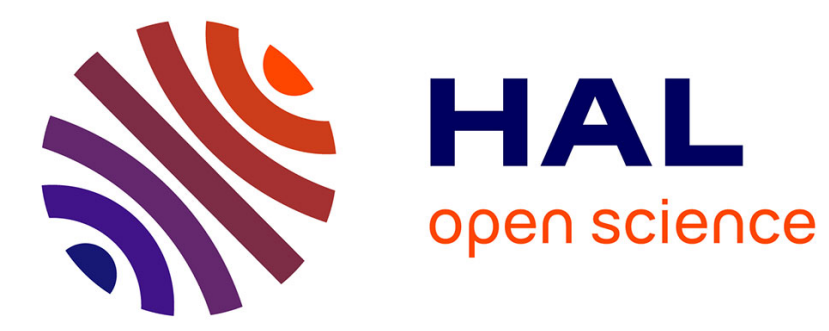

\title{
Self-Assembly of PEG-b-PTMC Copolymers: Micelles and Polymersomes Size Control
}

\author{
Coralie Lebleu, Laura Rodrigues, Jean-Michel Guigner, Annie Brûlet, \\ Elisabeth Garanger, Sébastien Lecommandoux
}

\section{- To cite this version:}

Coralie Lebleu, Laura Rodrigues, Jean-Michel Guigner, Annie Brûlet, Elisabeth Garanger, et al.. SelfAssembly of PEG-b-PTMC Copolymers: Micelles and Polymersomes Size Control. Langmuir, 2019, 35 (41), pp.13364-13374. 10.1021/acs.langmuir.9b02264 . hal-02306925

\section{HAL Id: hal-02306925 \\ https://hal.science/hal-02306925}

Submitted on 13 Mar 2020

HAL is a multi-disciplinary open access archive for the deposit and dissemination of scientific research documents, whether they are published or not. The documents may come from teaching and research institutions in France or abroad, or from public or private research centers.
L'archive ouverte pluridisciplinaire HAL, est destinée au dépôt et à la diffusion de documents scientifiques de niveau recherche, publiés ou non, émanant des établissements d'enseignement et de recherche français ou étrangers, des laboratoires publics ou privés. 


\section{Self-assembly of PEG- $b$-PTMC copolymers:} micelles and polymersomes size control

Coralie Lebleu, ${ }^{\dagger+}$ (D) Laura Rodrigues, ${ }^{\dagger *}$ (D) Jean-Michel Guigner, ${ }^{\$}$ Annie Brûlet, ${ }^{I}$ Elisabeth Garanger,,$^{\dagger}$ (D) Sébastien Lecommandoux ${ }^{\dagger} *$ (D)

† Univ. Bordeaux, CNRS, Bordeaux INP, LCPO, UMR 5629, F-33600, Pessac, France.

\$ Institut de Minéralogie, de Physique des Matériaux et de Cosmochimie (IMPMC), Sorbonne Universités, IRD, CNRS UMR 7590, MNHN, 75252 Paris Cedex 05, France.

I Laboratoire Léon Brillouin (LLB), CEA-Saclay, CNRS UMR 12, 91191 Gif-sur-Yvette Cedex, France.

S Supporting Information 


\section{ABSTRACT}

Poly(ethylene glycol) ${ }_{45}-b$-poly(trimethylene carbonate) ${ }_{\mathrm{n}} \mathrm{PEG}_{45}-b-\mathrm{PTMC}_{\mathrm{n}}$ diblock copolymers were synthesized with five different PTMC degrees of polymerization $(n=38,96,144,170$, 332) and their self-assembly properties in water were studied using a manual nanoprecipitation procedure. We confirmed that the copolymer's hydrophilic weight fraction $\left(f_{\mathrm{PEG}}\right)$ is controlling nanoparticles morphology. We determined that the $\mathrm{PEG}_{45}-b$-PTMC 96 with $\mathrm{f}_{\mathrm{PEG}} \approx 17 \%$ is the optimal hydrophilic fraction for the stabilization of well-defined unilamellar vesicles with a membrane thickness of $\delta \approx 14.6 \mathrm{~nm}$. Maintaining this fraction constant and modulating the overall molar mass of the block copolymers allowed the establishment of a power law of $\delta \propto \bar{M}_{n}^{0.56}$ which provides a robust correlation between the molar mass of PTMC and vesicles' membrane thickness. Finally, we proved that controlling nanoprecipitation's conditions by microfluidics allowed fine-tuning and control of the nanoparticles size and polydispersity index while maintaining their shape with a perfect batch-to-batch reproducibility. 


\section{INTRODUCTION}

In recent years, polymeric nanoparticles have been widely investigated as drug delivery systems with some currently being under clinical trials. ${ }^{1-4}$ Among the different nanocarriers being developed, a significant part are resulting from the self-assembly of amphiphilic block copolymers in aqueous solution in different morphologies such as micelles, vesicles or rods. ${ }^{5-}$ 7

Polymeric vesicles - also called polymersomes (Ps) - are of great interest for imaging purposes and as drug delivery systems in various types of therapy, the most explored being cancer treatment. $^{8-12}$

Compared to their low molar mass lipidic analogs, ${ }^{13}$ polymersomes have a thicker hydrophobic membrane, providing significant storage capacity for water-insoluble substances. They are also enclosing a large hydrophilic reservoir which can be loaded with water-soluble substances. Their surface can be (multi)functionalized with imaging probes and/or targeting moieties. Their membrane thickness dictates several physico-chemical properties such as colloidal stability, fluidity and permeability which can be easily modulated by tuning the hydrophobic block molar mass. ${ }^{14-18}$ Membrane permeability can also be tuned by changing the nature of the hydrophobic block or by chemical post-polymerization modifications. ${ }^{19-21}$

The formation of a majority of vesicles over other morphologies can be predicted by the use of a copolymer with a specific hydrophilic weight fraction (f). ${ }^{5}$ However, this tool can only be employed for objects obtained at or close to thermodynamic equilibrium. Indeed, it was shown that the same amphiphilic copolymer can form a variety of kinetically-trapped morphologies according to the formulation process. ${ }^{5,16,22}$ Generally speaking, one can anticipate that when increasing $\mathrm{f}$, self-assembled morphologies pass from vesicles to rods to micelles. $^{23}$ 
Ps can be obtained in different sizes through different formulation techniques such as film hydration or solvent-displacement method (also called nanoprecipitation). ${ }^{22,24}$ Microfluidic systems are particularly interesting for the formation of monodisperse, size-controlled Ps since they allow the mixture between solutions to be controlled and easily tuned in a repeatable manner (e.g. flow ratios between solutions and overall total flow rate) ${ }^{22,25-28}$ This permits reproducibility which is absolutely necessary for the development of Ps as drug delivery systems.

The copolymer's chemical nature is also important in order to access Ps with specific properties such as biodegradability or stimuli-responsiveness. ${ }^{29-32}$ Poly(ethylene glycol) (PEG) is often used as a hydrophilic block since it was found to delay Ps clearance from the blood. ${ }^{33,34}$ Biodegradable polymers, especially aliphatic polyesters and polycarbonates, such as poly(lactic acid) (PLA), polycaprolactone (PCL) and poly(trimethylene carbonate) (PTMC), are well studied in pharmaceutics due to their low systemic toxicity. ${ }^{35}$ For instance, after studying PEG- $b$-PLA and PEG- $b$-PCL self-assembly and stability, Discher et $a l$. showed they could form polymersomes which biodegrade upon hydrolysis. ${ }^{36}$ Recently, PTMC-based materials were investigated since PTMC has a unique degradation which is mostly sensitive to enzymatic hydrolysis with a surface erosion mechanism generating non-acidic products. ${ }^{37,38}$ Our group demonstrated the stability in aqueous conditions and enzymatic degradation of vesicles made from PGA- $b$-PTMC copolymers presenting an anionic poly $(\mathrm{L}-$ glutamic acid) (PGA) as the hydrophilic block. ${ }^{22}$ In addition, we determined that the PTMC semi-crystalline nature impacted the PTMC conformation in the membrane. ${ }^{39}$

Because PEG is routinely employed as a hydrophilic block for its stealthiness property, the self-assembly of PEG- $b$-PTMC copolymers was also studied. Van Hest and co-workers reported the formation of PEG- $b$-PTMC multilamellar vectors ${ }^{40}$ or micelles ${ }^{41}$, while Fang and co-workers. ${ }^{42}$ formed spherical nanoparticles without elucidating their shape in deep details. 
To our knowledge, only two articles showed the possible formation of PEG- $b$-PTMC vesicles: Feijen's team mentioned that a $\mathrm{PEG}_{5.8 \mathrm{k}}-b-\mathrm{PTMC}_{24 \mathrm{k}}\left(\mathrm{f}_{\mathrm{PEG}}=19.5 \%\right)$ could form polymersomes $^{43}$ and Zhong and co-workers confirmed that this hydrophilic fraction was suitable to preferentially form vesicles with $-\mathrm{COOH}$ or $-\mathrm{NH}_{2}$ terminated $\mathrm{PEG}_{5 \mathrm{k}}-b-\mathrm{PTMC}_{20.3 \mathrm{k}}$ $\left(f_{\mathrm{PEG}}=19.8 \%\right) .{ }^{44}$ This value of $\mathrm{f}_{\mathrm{PEG}}$ was not following the empirical rule of Discher \& Eisenberg of $25 \%<\mathrm{f}_{\mathrm{PEG}}<45 \%$ that were established for polydiene based copolymers. ${ }^{5}$ This is not surprising since diblock copolymers made of PEG and polar polymers such as PLA or PCL were shown to form vesicles for $\mathrm{f}_{\mathrm{PEG}}<20 \%{ }^{23}$

The purpose of our study was to obtain monodispersed and size-controlled PEG- $b$-PTMC polymersomes with different PTMC membrane thicknesses while keeping the length of PEG constant at $2000 \mathrm{~g} / \mathrm{mol}$, this molar mass being often reported to provide interesting stealth behavior. ${ }^{34}$ To reach this goal, we first synthesized and characterized a series of amphiphilic block copolymers, $\mathrm{PEG}_{45}-b$-PTMC , with different PTMC block length. We then studied the influence of the copolymer's hydrophilic weight fraction ( $\left.f_{\mathrm{PEG}}\right)$ on nanoparticles morphology obtained upon self-assembly in water by manual nanoprecipitation. Finally, we studied the impact of nanoprecipitation conditions by microfluidics on nanoparticles' size and polydispersity index.

\section{EXPERIMENTAL SECTION}

\section{Materials}

Solvents: tetrahydrofuran (THF), dimethyl sulfoxide (DMSO), ethyl acetate, toluene, acetic acid, methanol) were purchased from Sigma-Aldrich. THF was dried by a solvent purification system. Trimethylene carbonate (1,3-dioxane-2-one; TMC) was purchased from TCI Europe and purified by three successive recrystallizations in dry ethyl acetate. Poly(ethylene glycol)methyl ether $\left(\mathrm{MeO}-\mathrm{PEG}_{45}-\mathrm{OH} ; \overline{M_{n}}=2000 \mathrm{~g} / \mathrm{mol}\right)$ was purchased from Iris Biotech 
GMBH and dried by azeotropic distillation in toluene. DBU (1,8-diazabicyclo[5.4.0]undec-7ene) was purchased from Sigma-Aldrich and distilled before use.

\section{Synthesis of PEG-b-PTMC block copolymers}

The synthesis of the $\mathrm{PEG}_{45}-b-\mathrm{PTMC}_{\mathrm{n}}$ block copolymers was adapted from a previously described method of ring-opening polymerization (ROP) of TMC using MeO-PEG-OH as a macro-initiator (Scheme 1). ${ }^{45}$ All the compounds and solvents must be anhydrous or distilled to avoid secondary reactions with water. All polymerization reactions were performed in flame-dried glassware employing standard high vacuum techniques and carried out in a glovebox under inert atmosphere (argon, $\left[\mathrm{O}_{2}\right]<0.5 \mathrm{ppm},\left[\mathrm{H}_{2} \mathrm{O}\right]<5 \mathrm{ppm}$ ).

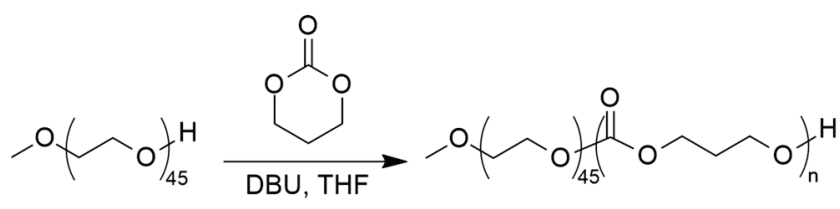

Scheme 1. Reaction scheme of the synthesis of $\mathrm{PEG}_{45}-b-\mathrm{PTMC}_{\mathrm{n}}$ by ring-opening polymerization (ROP) of TMC on $\mathrm{MeO}-\mathrm{PEG}_{45}-\mathrm{OH}$ in THF and initiated by DBU.

The procedure described below was used for a targeted PTMC degree of polymerization (DP) of 40 and adapted for DPs 120, 190 and 400. In a glovebox, dry THF (2 mL) was added in a Schlenk containing dried MeO-PEG $45-\mathrm{OH}(2.2 \mathrm{~g}, 1.1 \mathrm{mmol})$ and let to stir until total dissolution. Separately, TMC (previously recrystallized, $4 \mathrm{~g}, 39 \mathrm{mmol}$ ) was dissolved in dry THF (6 mL). The TMC solution was added to the PEG solution. DBU (previously distilled, $161 \mu \mathrm{L}, 1.1 \mathrm{mmol})$ was introduced and the mixture was left to stir at room temperature. The reaction progress was checked by ${ }^{1} \mathrm{H}$ NMR of the reaction mixture. When the PTMC DP was reached ( $95 \%$ of conversion), the reaction was quenched with an excess of acetic acid. The resulting copolymer was precipitated in cold methanol, centrifuged to remove the supernatant, 
washed 3 more times with cold methanol and dried under vacuum overnight. The pure copolymer was obtained as a white powder.

${ }^{1} \mathrm{H}$ NMR (400 MHz, $\mathrm{CDCl}_{3}, \delta$ ppm): 4.29 (2H, -PTMC $\left.\mathrm{n}_{-1}-\mathrm{CO}-\mathrm{O}-\mathrm{CH}_{2}-\mathrm{CH}_{2}-\mathrm{CH}_{2}-\mathrm{OH}\right) ; 4.23$ $\left(\mathrm{t}, \mathrm{J}=8.34 \mathrm{~Hz}, 4^{*}(\mathrm{n}-1) \mathrm{H},-\left(\mathrm{CO}-\mathrm{O}-\mathrm{CH}_{2}-\mathrm{CH}_{2}-\mathrm{CH}_{2}-\mathrm{O}\right)_{\mathrm{n}-1^{-}}\right) ; 3.73\left(2 \mathrm{H},-\mathrm{PTMC}_{\mathrm{n}-1}-\mathrm{CO}-\mathrm{O}-\mathrm{CH}_{2}-\right.$ $\left.\mathrm{CH}_{2}-\mathrm{CH}_{2}-\mathrm{OH}\right) ; 3.63$ (s, (4*45)H, -(- $\left.\left.\mathrm{CH}_{2}-\mathrm{CH}_{2}-\mathrm{O}\right)_{45^{-}}\right) ; 3.37$ (s, 3H, $\left.\mathbf{H}_{3} \mathrm{C}-\mathrm{O}-\mathrm{PEG}-\right) ; 2.04$ (quint, $\mathrm{J}=8.34 \mathrm{~Hz}, 2^{*}(\mathrm{n}-1) \mathrm{H},-\left(\mathrm{CO}-\mathrm{O}-\mathrm{CH}_{2}-\mathrm{CH}_{2}-\mathrm{CH}_{2}-\mathrm{O}\right)_{\mathrm{n}-1^{-}}$); 1.91 (quint, $\mathrm{J}=8.12 \mathrm{~Hz}, 2 \mathrm{H}$,$\left.\mathrm{PTMC}_{\mathrm{n}-1}-\mathrm{CO}-\mathrm{O}-\mathrm{CH}_{2}-\mathrm{CH}_{2}-\mathrm{CH}_{2}-\mathrm{OH}\right)$.

\section{Formulation of nanoparticles}

Manual nanoprecipitation (mNP). Ultrapure water and copolymer solution in DMSO (10 $\mathrm{g} / \mathrm{L})$ were respectively filtered off with cellulose acetate $0.22 \mu \mathrm{m}$ and polytetrafluoroethylene (PTFE) $0.45 \mu \mathrm{m}$ syringe filters. Filtered water $(2.7 \mathrm{~mL})$ was quickly added in the filtered copolymer solution under stirring $\left(400 \mathrm{rpm}, 25^{\circ} \mathrm{C}, 300 \mu \mathrm{L}\right.$ of a $10 \mathrm{~g} / \mathrm{L}$ solution) to obtain a suspension at $1 \mathrm{~g} / \mathrm{L}$ of copolymer and $90 \mathrm{vol} \%$ of water. To remove the organic solvent, the suspension was dialyzed against deionized water using a $3.5 \mathrm{kD}$ cut-off dialysis membrane (Spectra/Por ${ }^{\circledR} \mathrm{RC}, 5 \mathrm{~L}$ of water, 2 changes). With the $\mathrm{PEG}_{45}-b-\mathrm{PTMC}_{96}$ copolymer, the reverse addition (mNP-ra) was also performed at 90 vol\% of water by quickly adding under stirring the filtered copolymer solution ( $400 \mathrm{rpm}, 25{ }^{\circ} \mathrm{C}, 300 \mu \mathrm{L}$ of a $10 \mathrm{~g} / \mathrm{L}$ solution) into filtered ultrapure water $(2.7 \mathrm{~mL})$.

Controlled nanoprecipitation using a microfluidic system (cNP). The Dolomite Microfluidics ${ }^{\circledR}$ system used was constituted of: two pressure pumps (3200175), two flow rate sensors (3200097) and a micromixer chip (3200401) all connected with FEP tubing (1/16" x $0.25 \mathrm{~mm}, 3200063)$. Under nitrogen pressure, flow rates were controlled by the Mitos Flow Control Center 2.5.17 software. A scheme of the set-up is available in Figure S7. Ultrapure water and copolymer solution in DMSO $(1 \mathrm{~g} / \mathrm{L})$ were respectively filtered off with cellulose acetate $0.22 \mu \mathrm{m}$ and PTFE $0.45 \mu \mathrm{m}$ syringe filters. One pump was filled with the filtered 
copolymer solution in DMSO (P-DMSO) and connected to the chip through the first and third inputs using a T-connector. The other pump was filled with filtered ultrapure water and directly linked to the chip through the second input. A camera was used to verify that the chip was dust free and air bubbles free. Flow rates were set at $233 \mu \mathrm{L} / \mathrm{min}$ of P-DMSO for 100 $\mu \mathrm{L} /$ min of $\mathrm{H}_{2} \mathrm{O}$. Suspension (333 $\mu \mathrm{L} / \mathrm{min}$ total flow rate; 30 vol\% water content) was collected into a glass vial from the chip's output after 12 mixing stages. The organic solvent was removed by dialysis against deionized water using a $3.5 \mathrm{kD}$ cut-off dialysis membrane (Spectra/Por ${ }^{\circledR} \mathrm{RC}, 5 \mathrm{~L}$ of water, 2 changes). With the $\mathrm{PEG}_{45}-b$-PTMC 96 copolymer, different conditions were tested to apprehend the system (Figure S8 and Table S3). All suspensions were prepared at room temperature.

\section{Characterization techniques}

NMR. Nuclear magnetic resonance (NMR) experiments were performed at $298 \mathrm{~K}$ on a Bruker Avance I NMR spectrometer operating at $400 \mathrm{MHz}$, using TMS as standard, and equipped with a Bruker multinuclear $\mathrm{z}$ gradient direct probe head capable of producing gradients in the $\mathrm{z}$ direction with 53.5 G.cm ${ }^{-1}$ strength. ${ }^{1} \mathrm{H}$ NMR spectra were recorded with a D1 of $5 \mathrm{~s}$ and 32 scans. To describe the multiplicities of the signals, the following abbreviations were used: s: singlet, t: triplet and quint: quintuplet. The coupling constants, abbreviated J, were expressed in Hz.

SEC. Size exclusion chromatography (SEC) analyses were performed on a Varian apparatus equipped with a refractive index detector and a three-column set of TSK gel TOSOH (G2000HXL, G3000HXL, G4000HXL with pore sizes respectively of 20, 75, and $200 \AA$ ). Analyses were carried out on polymer samples $(10 \mathrm{mg} / \mathrm{mL})$ at $40{ }^{\circ} \mathrm{C}$ using $\mathrm{THF}$ as eluent $(1 \mathrm{~mL} / \mathrm{min})$ and trichlorobenzene as a flow marker. Values of the refractive index increment $(\mathrm{dn} / \mathrm{dc})$ of each copolymer were determined by measuring the differential refractive index between copolymer solutions at different concentrations (1, 5, 10 and $15 \mathrm{~g} / \mathrm{L})$ and pure 
THF using the refractive index detector of the Varian apparatus. The $\mathrm{dn} / \mathrm{dc}$ corresponds to the slope of the linear regression of the differential refractive index values against the copolymer concentration. The $\mathrm{dn} / \mathrm{dc}$ values were then used to determine the true copolymer's average molar mass $\left(\overline{M_{n}}\right)$ and dispersity $(Đ)$.

TGA. Thermogravimetric analyses (TGA) were performed on a TA Instruments Q500 under a continuous nitrogen flow using approximatively $8 \mathrm{mg}$ of samples in a platinum pan. The heating run was recorded at $10{ }^{\circ} \mathrm{C} / \mathrm{min}$ from room temperature to $500{ }^{\circ} \mathrm{C}$.

DSC. Differential scanning calorimetry (DSC) analyses were carried out on a TA Instruments Q100 under a continuous flow of nitrogen and helium $(25 \mathrm{~mL} / \mathrm{min})$, using approximatively $5 \mathrm{mg}$ of samples in sealed aluminum pans. Thermograms of three successive runs were recorded: (i) first heating run from -60 to $120{ }^{\circ} \mathrm{C}$ at $10{ }^{\circ} \mathrm{C} / \mathrm{min}$; (ii) cooling run from 120 to $-60{ }^{\circ} \mathrm{C}$ at $10{ }^{\circ} \mathrm{C} / \mathrm{min}$; (iii) second heating run from -60 to $80{ }^{\circ} \mathrm{C}$ at $10{ }^{\circ} \mathrm{C} / \mathrm{min}$. As the crystallization process of the copolymers was slow, the melting temperature $\left(\mathrm{T}_{\mathrm{m}}\right)$ and the glass transition temperature $\left(\mathrm{T}_{\mathrm{g}}\right)$ were measured only on the first heating run.

DLS 90 ${ }^{\circ}$. Dynamic light scattering measurements (DLS 90 ${ }^{\circ}$ were carried out on a Malvern Zetasizer Nano ZS equipped with a He-Ne laser $(633 \mathrm{~nm})$, at $25^{\circ} \mathrm{C}$ and a scattering angle of $90^{\circ}$. Values of viscosity were corrected according to the mixture of $\mathrm{DMSO} / \mathrm{H}_{2} \mathrm{O}$ used. Hydrodynamic radius $\left(\mathrm{R}_{\mathrm{h}}\right)$ of the nanoparticles and polydispersity index (PDI) were calculated from autocorrelation functions using the cumulant method.

MALS. Multi-angle dynamic and static light scattering (MALS) measurements were performed using an ALV-5000 goniometer with a He-Ne laser (633 nm) and an ALV5000/EPP multiple tau digital correlator (initial sampling time of $125 \mathrm{~ns}$ ). Suspensions at 0.1 $\mathrm{g} / \mathrm{L}$ of copolymer were placed in $10 \mathrm{~mm}$ outer diameter quartz tubes. Temperature of the toluene bath was set at $25^{\circ} \mathrm{C}$. Data were acquired on the ALV correlator software at several angles from $30^{\circ}$ to $150^{\circ}$ by step of $10^{\circ}$ (counting time of $10 \mathrm{~s}$ ). The hydrodynamic radii $\left(\mathrm{R}_{\mathrm{h}}\right)$ 
and PDI were determined using the cumulant method. The radii of gyration $\left(\mathrm{R}_{\mathrm{g}}\right)$ were calculated using Guinier's approximation.

Cryo-TEM. Cryo-transmission electron microscopy (cryo-TEM) images were recorded at the Institut de Minéralogie, de Physique des Matériaux et de Cosmochimie (Paris) on a LaB6 JEOL 2100 (JEOL, Japan) working at $200 \mathrm{kV}$. Samples were prepared by placing a drop of a suspension of nanoparticles onto a holey carbon grid (Quantifoil ${ }^{\circledR}$ Micro Tools GmbH, Germany). Excess of solution was blotted by a filter paper. The grid was rapidly plunged into liquid ethane, placed onto a Gatan 626 cryo-holder and transferred into the microscope. The grids were observed at low temperature $\left(-180^{\circ} \mathrm{C}\right)$ and under low dose conditions (JEOL minimum dose system). Pictures were taken with an Ultrascan 2k CDD camera (Gatan, USA) and analyzed with the Image J software.

SANS. Small angle neutron scattering experiments (SANS) were performed at the Laboratoire Léon Brillouin (CEA-CNRS, Saclay) on the PACE and PA20 spectrometers. Four configurations were chosen by varying the wavelength $\lambda$ and the sample-to-detector distance $D$, to cover a large range of scattering vectors $q\left(q=\frac{4 \pi}{\lambda} \sin \left(\frac{\theta}{2}\right)\right)$ from $1.1 \times 10^{-3}$ to $1.1 \times 10^{-1} \AA^{-1}$ : i) $\lambda=6 \AA, D=3 \mathrm{~m}$; ii) $\lambda=6 \AA, D=5 \mathrm{~m}$; iii) $\lambda=13 \AA, D=5 \mathrm{~m}$ (on PACE) and iv) $\lambda=13 \AA, D=16 \mathrm{~m}$ (on PA20). Analyses were done on samples in $\mathrm{D}_{2} \mathrm{O}$ at approximately $1 \mathrm{~g} / \mathrm{L}$ of copolymer.

Samples were first prepared in $\mathrm{H}_{2} \mathrm{O}$ and the change of solvent to $\mathrm{D}_{2} \mathrm{O}$ was done using an ultrafiltration system (10 mL Amicon Millipore stirred cell, Ultracel ${ }^{\circledR}$ disc of $100 \mathrm{kD}$ cut-off). Suspensions in $\mathrm{H}_{2} \mathrm{O}$ were diluted 5 times with $\mathrm{D}_{2} \mathrm{O}$ (Euriso-Top ${ }^{\circledR}$ ), concentrated, washed a second time and concentrated again.

Samples were placed into Thuet ${ }^{\circledR}$ quartz cells of $5 \mathrm{~mm}$ optical path length. Absolute values of the scattering intensity, $I(q)$, (in $\mathrm{cm}^{-1}$ ) were obtained from the direct determination of the incident beam flux. ${ }^{46}$ 
Scattering intensity from $N$ identical particles of spherical symmetry with a volume $V_{P}$ placed in a total volume $V$ can be expressed as follows:

$$
I(q)=\Phi(\Delta \rho)^{2} V_{P} P(q) S(q)
$$

where $P(q)$ is the form factor of the particles, $S(q)$ the structure factor, $\Phi=\frac{N V_{P}}{V}$ the volume fraction and $(\Delta \rho)^{2}$ is the contrast, with $\Delta \rho$ the difference of scattering length densities between particle and solvent. Assuming that PEG chains were highly hydrated by $\mathrm{D}_{2} \mathrm{O}$, we considered $\Delta \rho$ only between PTMC and $\mathrm{D}_{2} \mathrm{O}\left(\Delta \rho=4.70 * 10^{-6} \AA^{-2}\right)$.

Scattering curves were analyzed by fitting them with theoretical curves using SasView software (http://www.sasview.org), considering the background, volume fraction, scattering length densities of polymer and solvent, object polydispersity and measurement uncertainties $(d q$ and $d I)$.

Different form factors were used to fit the data: sphere, vesicle and vesicular aggregate.

Sphere model is the historical model used by Guinier where $R$ is the sphere radius.

$$
P(q)=\left[3 \frac{\sin (q R)-q R \cos (q R)}{(q R)^{3}}\right]^{2}
$$

Vesicle model is a shell model where particles are defined by spherical shells of PTMC:

$$
P(q)=\frac{1}{\left(V_{e}-V_{c}\right)^{2}}\left[3 V_{e} \frac{\sin \left(q R_{e}\right)-q R_{e} \cos \left(q R_{e}\right)}{\left(q R_{e}\right)^{3}}-3 V_{c} \frac{\sin \left(q R_{c}\right)-q R_{c} \cos \left(q R_{c}\right)}{\left(q R_{c}\right)^{3}}\right]^{2}
$$

where $\left(R_{e}, R_{c}\right)$ and $\left(V_{e}, V_{c}\right)$ are respectively the external and core radii and volumes and $\delta=R_{e}-R_{c}$ the hydrophobic membrane thickness.

Vesicular aggregate model is a fractal aggregate model of core-shell particles. ${ }^{47}$ Here, for:

$$
\begin{gathered}
I(q)=\phi P(q) S(q) \\
P(q)=\frac{1}{V_{e}}\left[3 V_{c}\left(\rho_{c}-\rho_{s}\right) \frac{\sin \left(q R_{c}\right)-q R_{c} \cos \left(q R_{c}\right)}{\left(q R_{c}\right)^{3}}+3 V_{e}\left(\rho_{s}\right.\right. \\
\left.\left.-\rho_{D_{2} O}\right) \frac{\sin \left(q R_{e}\right)-q R_{e} \cos \left(q R_{e}\right)}{\left(q R_{e}\right)^{3}}\right]^{2}
\end{gathered}
$$

and: 


$$
S(q)=1+\frac{D_{f} \Gamma\left(D_{f}-1\right)}{\left[1+1 /(q \xi)^{2}\right]^{\left(D_{f}-1\right) / 2}} \sin \left[\left(D_{f}-1\right) \tan ^{-1}(q \xi)\right]
$$

where $\left(R_{e}, R_{c}, R_{s}\right),\left(V_{e}, V_{c}, V_{s}\right)\left(\rho_{e}, \rho_{c}, \rho_{s}\right)$ are respectively the radii, the volumes and scattering length densities of the whole particle, core and shell. $D_{f}$ is the fractal dimension and $\xi$ the correlation length of the fractal aggregates.

For all models, the radius polydispersity $\sigma_{R}$ was estimated as a standard deviation of a lognormal distribution whereas the thickness polydispersity $\sigma_{\delta}$ was done on a gaussian distribution. Standard deviations $\left(\mathrm{SD}_{\mathrm{R}}, \mathrm{SD}_{\delta}\right)$ were calculated for the radius and the thickness by multiplying the respective polydispersity $\left(\sigma_{R}, \sigma_{\delta}\right)$ with either the value of the radius $(\mathrm{R})$ or of the thickness $(\delta)$.

\section{RESULTS AND DISCUSSION}

\section{Synthesis of copolymers and characterization}

A series of poly(ethylene glycol)- $b$-poly(trimethylene carbonate) $\mathrm{PEG}_{45}-b$-PTMC $\mathrm{n}_{\mathrm{n}}$ block copolymers was obtained by ring-opening polymerization (ROP) using $\mathrm{MeO}-\mathrm{PEG}_{45}-\mathrm{OH}\left(\overline{M_{n}}\right.$ $=2000 \mathrm{~g} / \mathrm{mol}$ ) as macro-initiator in the presence of DBU as catalyst (Scheme 1).

The DP ( $\mathrm{n}$ value) of the PTMC block was easily calculated by proton NMR in $\mathrm{CDCl}_{3}$ from the integration of the resonance peaks at 2.04 and $4.23 \mathrm{ppm}$ corresponding to PTMC protons. The calibration was performed based on the PEG block with peaks at 3.63 ppm (184H) and $3.37 \mathrm{ppm}(3 \mathrm{H})$ (Figure S1). The DP of PTMC was also determined by steric exclusion chromatography (SEC) in THF using each copolymer's actual refractive index increment $(\mathrm{dn} / \mathrm{dc})$. Both methods provided consistent and similar results.

Five block copolymers $\mathrm{PEG}_{45}-b-\mathrm{PTMC}_{\mathrm{n}}$ with $\mathrm{n}=38,96,144,177$ and 332 were synthesized with a hydrophilic weight fraction $f_{P E G}$ ranging from $34 \%$ to $6 \%$. Their 
characteristics found by NMR, SEC and differential scanning calorimetry (DSC) are summarized in Table 1.

SEC analyses in THF revealed a narrow molar mass distribution of the copolymers (dispersity Đ ranging from 1.05 to 1.17 ) (Figure S2). Thermogravimetric analyses (TGA) provided information on the copolymers degradation and purity (Figure S3). The first block to be degraded was the PTMC around $200{ }^{\circ} \mathrm{C}$ followed by the one of PEG around $320{ }^{\circ} \mathrm{C}$. The larger the PTMC block, the higher its degradation temperature. There were no carbon residues at $500{ }^{\circ} \mathrm{C}$ which corroborates the excellent purity of the copolymers evidenced by NMR and SEC.

Table 1. Characteristics of $\mathrm{PEG}_{45}-b-\mathrm{PTMC}_{\mathrm{n}}$ block copolymers obtained by ${ }^{1} \mathrm{H}$ NMR, SEC and DSC.

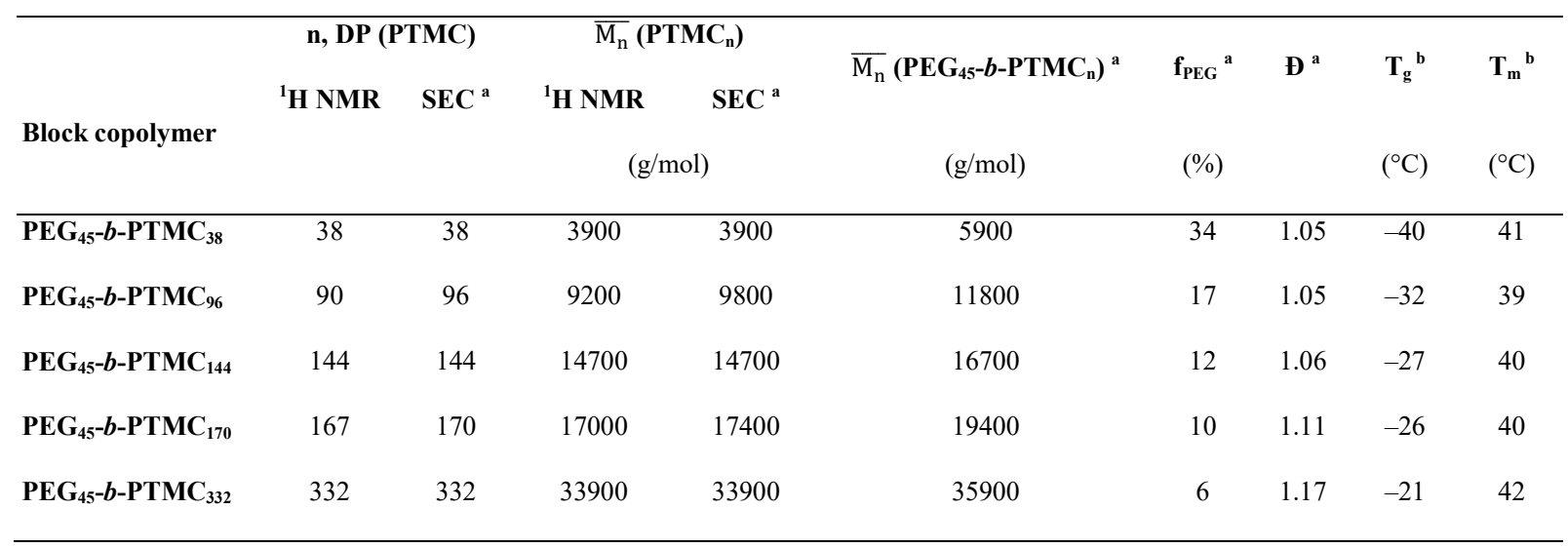

\footnotetext{
${ }^{a}$ Results from SEC in THF (Đ: dispersity)

${ }^{\mathrm{b}}$ Results from DSC

$\mathrm{n}$ : degree of polymerization (DP) of PTMC

$f_{\mathrm{PEG}}$ : ratio of the PEG molar mass on the copolymer molar mass

$\mathrm{T}_{\mathrm{g}}$ : glass transition temperature

$\mathrm{T}_{\mathrm{m}}$ : melting temperature (DSC)
} 
$\mathrm{PEG}_{45}-b-\mathrm{PTMC}_{\mathrm{n}}$ copolymers were also analyzed by DSC between $-60{ }^{\circ} \mathrm{C}$ and $120{ }^{\circ} \mathrm{C}$ (Figure 1). During the analysis, copolymers underwent a first heating run (Figure 1A), a cooling run (Figure 1B) and a second heating run (Figure 1C). The five copolymers had a glass transition temperature $\mathrm{T}_{\mathrm{g}}$ (Figure $1 \mathrm{C}$ ) between $-40{ }^{\circ} \mathrm{C}$ and $-21{ }^{\circ} \mathrm{C}$ (the $\mathrm{T}_{\mathrm{g}}$ increased when the DP of PTMC increased), as well as a melting temperature $\mathrm{T}_{\mathrm{m}}$ around $40{ }^{\circ} \mathrm{C}$ (Figure $1 \mathrm{~A}$, endothermic peak) which reflects the semi-crystalline nature of the $\mathrm{PEG}_{45}-b-\mathrm{PTMC}_{\mathrm{n}}$. However, there was no exothermic peak corresponding to the copolymer recrystallization during the cooling run (Figure 1B), and therefore no endothermic peak during the second heating run, except for $\mathrm{PEG}_{45}-b-\mathrm{PTMC}_{38}$, with the smallest DP of PTMC which indicates a probable very slow recrystallization kinetics. The thermal behavior of $\mathrm{PEG}_{45}-b$ - $\mathrm{PTMC}_{38}$ is actually different from the other copolymers, possibly because the PTMC is the shortest and its ratio in the copolymer is the lowest, both favoring its crystallization. Indeed, during the cooling run, the copolymer began to recrystallize around $0{ }^{\circ} \mathrm{C}$ (Figure 1B) and continued during the second heating run (Figure $1 \mathrm{C}$ ). Recrystallization kinetics at $21^{\circ} \mathrm{C}$ were performed by DSC analyses for $\mathrm{PEG}_{45}-b-\mathrm{PTMC}_{\mathrm{n}} \mathrm{n}=96,144,170$ and 332 in order to estimate the required time for the beginning of recrystallization (Figure S4 and Table S1). Results showed that the higher the ratio of PTMC in the copolymer, the slower the recrystallization (between a few minutes to several weeks), in good agreement with the work of Zhu et ll $^{48}$ This parameter could be important to consider concerning the self-assembly properties of the copolymers, especially when using a direct dissolution method. Oppositely, if nanoprecipitation is used, the process is so fast that this phenomenon is negligible, especially when small nanoparticles are obtained, leading to a strong confinement of PTMC chains. ${ }^{39}$ 


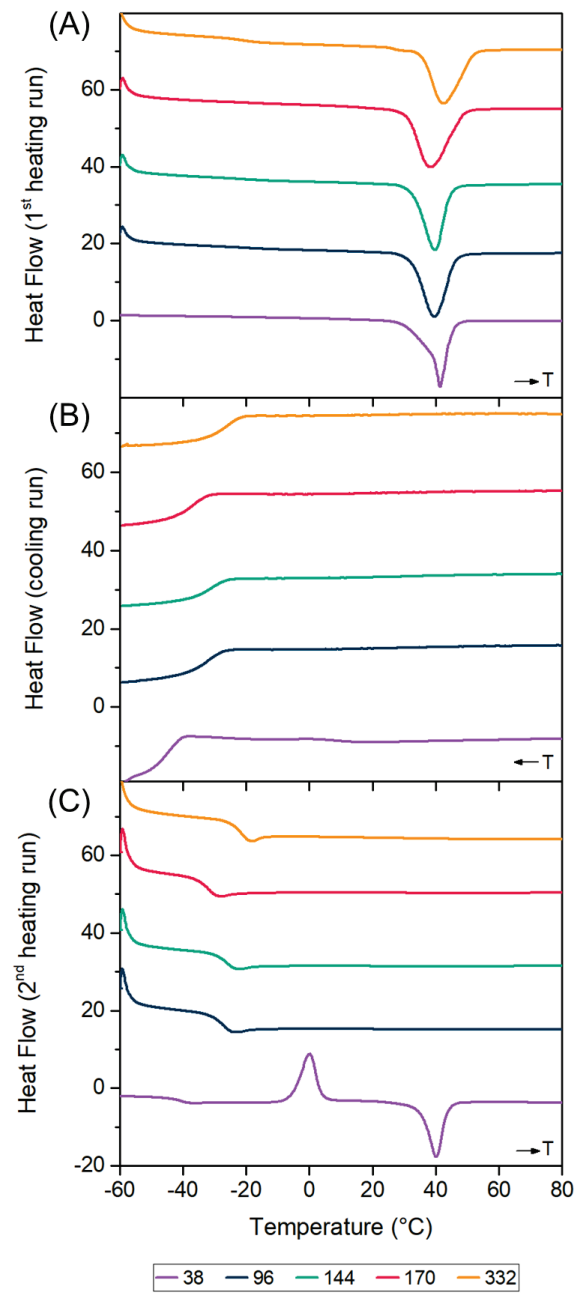

Figure 1. DSC thermograms of $\mathrm{PEG}_{45}-b-\mathrm{PTMC}_{\mathrm{n}}$ diblock copolymers $(\mathrm{n}=38$ (purple), 96 (blue), 144 (green), 170 (red), 332 (orange)). (A) First heating run; (B) Cooling run; (C) Second heating run. 


\section{Self-assembly}

Nanoparticles were prepared by self-assembly of the different $\mathrm{PEG}_{45}-b-\mathrm{PTMC}_{\mathrm{n}}$ diblock copolymers. In order to evaluate the influence of the copolymer's hydrophilic weight fraction on objects' size and morphology, the same formulation technique was applied to all copolymers.

\section{Direct dissolution}

We firstly investigated the direct dissolution method. Copolymers dissolution in water was performed for $\mathrm{PEG}_{45}-b-\mathrm{PTMC}_{96}$ and $\mathrm{PEG}_{45}-b-\mathrm{PTMC}_{144}$ at two different temperatures: below $\left(25^{\circ} \mathrm{C}\right)$ and above $\left(40^{\circ} \mathrm{C}\right)$ the copolymers' melting temperature. The objects hydrodynamic diameter $\left(\mathrm{D}_{\mathrm{h}}\right)$ and polydispersity index (PDI) were followed in time by dynamic light scattering (DLS) at $90^{\circ}$ (Figure S5). It took at least 1 week for the different systems to reach a state close to equilibrium, meaning to form only one population of sub-micron particles. In each case, the higher temperature $\left(40^{\circ} \mathrm{C}\right)$ allowed objects to be smaller. However, the impact of temperature on the polydispersity indexes (PDI) remains uncertain. Particles of $\mathrm{PEG}_{45}-b$ $\mathrm{PTMC}_{96}$ had a smaller PDI when formed at $25^{\circ} \mathrm{C}$ rather than $40{ }^{\circ} \mathrm{C}$, while the opposite situation was observed with $\mathrm{PEG}_{45}-b-\mathrm{PTMC}_{144}$ particles. Overall, the PDI improved with time but were still high ( $>0.2$ after 37 days of dissolution). Therefore, we decided to use another method to form monodisperse nanoparticles, namely a solvent-displacement method, also referred to as nanoprecipitation.

\section{Nanoprecipitation}

\section{Influence of the hydrophilic fraction}

We studied the self-assembly of the whole series of block copolymers by manual nanoprecipitation (mNP). In this process, water was manually added to each copolymer 
solution in DMSO to trigger the self-assembly and the organic solvent was then removed by dialysis against water.

mNP samples were produced in triplicate and each sample was analyzed by DLS at $90^{\circ}$ and both static and dynamic multi-angle light scattering (MALS). Size distributions obtained by DLS $90^{\circ}$ proved that NPs were spherical and monodisperse. Indeed, examples of DLS $90^{\circ}$ curves for one sample per type of NP (Figure 2A) showed narrow log-normal distributions without aggregation. Radius of gyration $\left(\mathrm{R}_{\mathrm{g}}\right)$ was estimated by plotting the scattered intensity from SLS measurement with a Guinier plot while hydrodynamic radius $\left(R_{h}\right)$ was calculated from DLS measurement using the Stokes-Einstein equation once the diffusion coefficient was determined using Fick's law of diffusion (Figure S6 and Table S2). All the NPs were found to have a hydrodynamic radius below $100 \mathrm{~nm}$ with a low dispersity $(\mathrm{PDI}<0.15)$ (Figure 2B). It could seem that the longer the PTMC in the copolymer, the larger the NPs. However, the manual nanoprecipitation procedure did not allow a perfect reproducibility of the size of the NPs (see standard deviations (SD) in Table S2). Repeatability was proven for mNP38, 96 and 332 since their size' SD was lower than $4 \mathrm{~nm}$ and their PDI' SD lower than 0.02 . It is thus possible to compare their sizes accurately and draw some conclusions: mNP38 were the smallest $\left(R_{h}=13 \pm 1 \mathrm{~nm}\right)$, mNP332 were the largest $\left(R_{h}=100 \pm 4 \mathrm{~nm}\right)$ and mNP96 were in between $\left(\mathrm{R}_{\mathrm{h}}=57 \pm 2 \mathrm{~nm}\right)$. However, repeatability was not achieved for mNP144 and 170 with respective size' SD of 13 and $21 \mathrm{~nm}$ meaning that their sizes could vary more than $20 \%$ of the mean value, even if at this stage of the characterization, it was not possible to explain the lack of repeatability of the manual nanoprecipitation only for these two copolymers.

The $R_{g} / R_{h}$ ratio was also calculated since it is representative of the objects morphology. ${ }^{49}$ Indeed, a vesicular shape should give $\mathrm{R}_{\mathrm{g}} / \mathrm{R}_{\mathrm{h}} \approx 1$ whereas $\mathrm{R}_{\mathrm{g}} / \mathrm{R}_{\mathrm{h}} \approx 0.67$ is expected for micellar structures. 
The $\mathrm{PEG}_{45}-b$-PTMC 38 nanoparticles $(\mathrm{mNP} 38)$ were the smallest, with $\mathrm{R}_{\mathrm{h}}=13 \pm 1 \mathrm{~nm}$, which was too low to be able to measure $\mathrm{R}_{\mathrm{g}}$ by static MALS. Even if we were not able to obtain the mNP38 $\mathrm{R}_{\mathrm{g}} / \mathrm{R}_{\mathrm{h}}$ ratio, the NPs' size strongly suggested spherical micelle morphology. Ratios $R_{g} / R_{h}$ of mNP96, 144, 170 and 332 were all found to be around 1, meaning that the objects were probably vesicles.

(A)

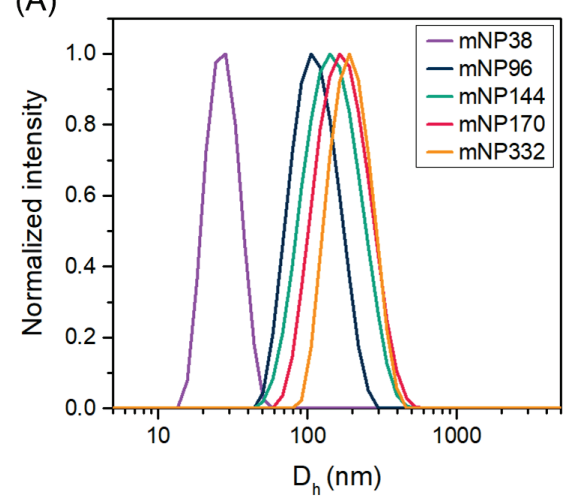

(B)

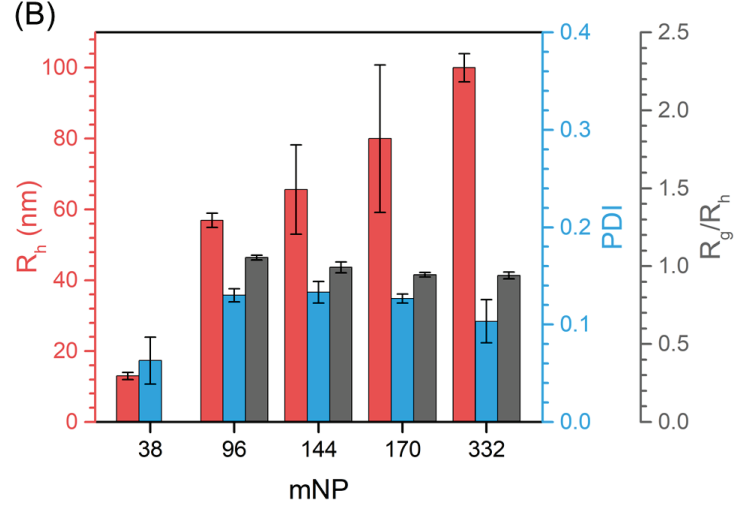

Figure 2. A) Example of size distributions obtained by DLS $90^{\circ}$ on the different types of nanoparticles produced by manual nanoprecipitation (mNP) using the series of $\mathrm{PEG}_{45}-b$ $\mathrm{PTMC}_{\mathrm{n}}$ diblock copolymers ( $\mathrm{n}=38$ (purple), 96 (blue), 144 (green), 170 (red), 332 (orange)). B) Average MALS data obtained for each sample of NPs produced in triplicate by mNP: $R_{h}$ (red), PDI (blue) and $\mathrm{R}_{\mathrm{g}} / \mathrm{R}_{\mathrm{h}}$ ratio (grey). $\mathrm{R}_{\mathrm{g}}$ for $\mathrm{mNP} 38$ could not be calculated (see example of Guinier plot in Figure S6A). Details of the data obtained for each sample in Table S2.

To further characterize the objects, cryo-transmission electron microscopy (cryo-TEM) experiments were performed for each type of nanoparticles obtained from mNP (Figure 3A). Different morphologies were observed: micelles for mNP38, unilamellar vesicles for mNP96, vesicular aggregates for mNP144 and 170 and a mixture of vesicular aggregates and spheres for mNP332.

Small angle neutron scattering (SANS) experiments were also performed to verify the supposed morphologies. All the samples were studied in $\mathrm{D}_{2} \mathrm{O}$ to have a better contrast 
between PTMC and solvent. Scattering curves were fitted with an appropriate model for the form factor which was chosen according to cryo-TEM pictures (Figure 3B). Data plots for mNP38 and 332 were well adjusted with a sphere model, mNP96 with a unilamellar vesicle model and mNP144 and 170 with a specific model of a fractal core-shell to mimic a vesicular aggregate.

All the characteristics obtained from DLS $90^{\circ}$, MALS, cryo-TEM and SANS are summarized in Table 2. They provided a detailed internal structure of the different types of nanoparticles.

The radius from DLS was found to be higher than the radii found by cryo-TEM and SANS. For these two techniques, both the instrumental limitation and the low contrast of PEG lead to an underestimation of the radius whereas DLS is more sensitive to larger objects and give a hydrodynamic radius comprising the PEG corona and the solvation layer. This explains the difference of size determined from these different methods. Thus, the size of the NPs was only discussed with the hydrodynamic radius from DLS while cryo-TEM and SANS were both employed to assess the hydrophobic membrane thickness $(\delta)$ of the vesicular structures obtained for mNP96, 144 and 170.

Values of $\delta$ were similar between cryo-TEM and SANS (Table 2). Standard deviations on $\delta$ found with both techniques were also comparable, meaning that $\delta$ measurements were equally precise. However, since SANS is statistically more relevant than cryo-TEM, we chose to discuss on $\delta_{\text {SANS }}$ values, which were the following: $14.6 \pm 1.5 \mathrm{~nm}$ for $\mathrm{mNP} 96,18.1 \pm 3.3 \mathrm{~nm}$ for $\mathrm{mNP} 144$ and $20.2 \pm 4.0 \mathrm{~nm}$ for $\mathrm{mNP} 170$.

The higher values of standard deviations for both mNP144 and 170 compared to mNP96 can be explained by the fact that they both are vesicular aggregates and not well-defined unilamellar vesicles like mNP96. 
(A)

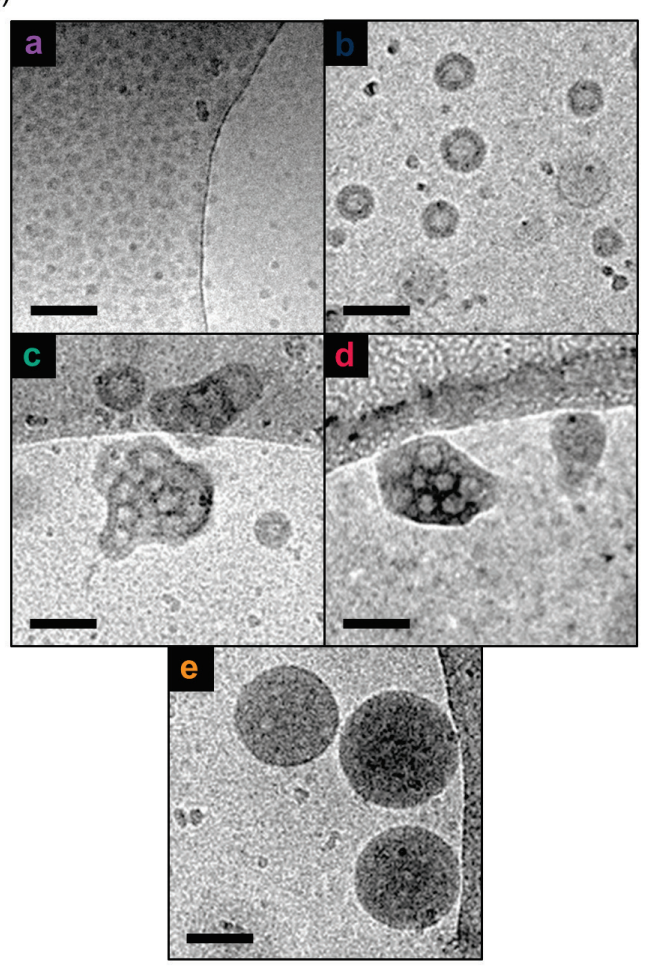

(B)

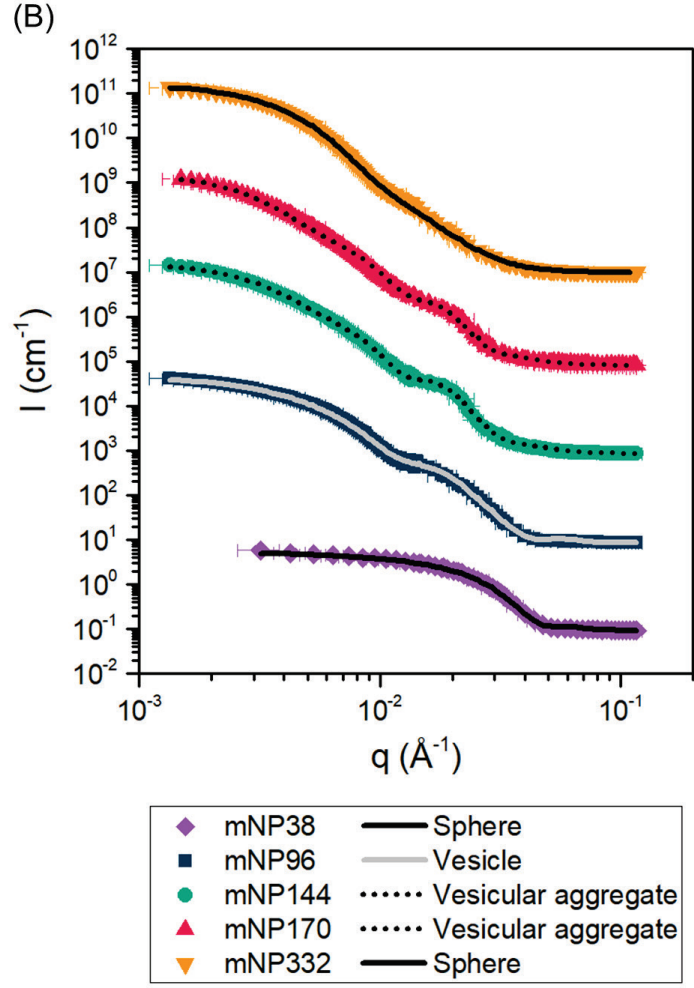

Figure 3. Cryo-TEM images (A) and SANS curves (B) of the different nanoparticles obtained by manual nanoprecipitation (mNP) using the series of $\mathrm{PEG}_{45}-b-\mathrm{PTMC}_{\mathrm{n}}$ diblock copolymers (n = 38 (purple, a), 96 (blue, b), 144 (green, c), 170 (red, d), 332 (orange, e)). A) Scale bar: $100 \mathrm{~nm}$. B) Neutron scattering curves were fitted with theoratical plots for different morphology models: sphere (black line), unilamellar vesicle (grey line) or vesicular aggregate (black dotted line) with $10^{2} \mathrm{~cm}^{-1}$ of offset between curves for clarity. 
Table 2. DLS $90^{\circ}$, MALS, cryo-TEM and SANS data obtained on the same nanoparticles formed by mNP and analyzed in $\mathrm{H}_{2} \mathrm{O}$ for DLS $90^{\circ}$ and MALS and $\mathrm{D}_{2} \mathrm{O}$ for cryo-TEM and SANS.

\begin{tabular}{|c|c|c|c|c|c|c|c|c|c|c|c|c|c|c|c|c|}
\hline \multirow[b]{2}{*}{ mNP } & \multicolumn{2}{|c|}{$\operatorname{DLS~90}^{\circ}$} & \multicolumn{3}{|c|}{ MALS } & \multicolumn{5}{|c|}{ Cryo-TEM } & \multicolumn{6}{|c|}{ SANS } \\
\hline & $\begin{array}{c}\mathrm{R}_{\mathrm{h}} \\
(\mathrm{nm})\end{array}$ & PDI & $\begin{array}{c}\mathrm{R}_{\mathrm{g}} \\
(\mathrm{nm})\end{array}$ & $\begin{array}{c}\mathrm{R}_{\mathrm{h}} \\
(\mathrm{nm})\end{array}$ & $\mathrm{R}_{\mathrm{g}} / \mathrm{R}_{\mathrm{h}}$ & $\mathrm{m}$ & $\begin{array}{c}\mathrm{R} \\
(\mathrm{nm})\end{array}$ & $\begin{array}{l}\mathrm{SD}_{\mathrm{R}} \\
(\mathrm{nm})\end{array}$ & $\begin{array}{c}\delta \\
(\mathrm{nm})\end{array}$ & $\begin{array}{l}\mathrm{SD}_{\delta} \\
(\mathrm{nm})\end{array}$ & $\mathrm{m}$ & $\begin{array}{c}\varphi \\
\left(10^{-4}\right. \\
\mathrm{g} / \mathrm{mL})\end{array}$ & $\begin{array}{c}\mathrm{R} \\
(\mathrm{nm})\end{array}$ & $\begin{array}{l}\mathrm{SD}_{\mathrm{R}} \\
(\mathrm{nm})\end{array}$ & $\begin{array}{c}\delta \\
(\mathrm{nm})\end{array}$ & $\mathrm{SD}_{\delta}$ \\
\hline 38 & 15 & 0.09 & - & 14 & - & $\mathrm{s}$ & 7.8 & 1.2 & - & - & $\mathrm{s}$ & 5.6 & 8.8 & 1.1 & - & - \\
\hline 96 & 55 & 0.13 & 53 & 51 & 1.04 & $\mathrm{v}$ & 37.3 & 15.0 & 14.6 & 1.6 & $\mathrm{v}$ & 8.8 & 30.1 & 10.5 & 14.6 & 1.5 \\
\hline 144 & 85 & 0.14 & 69 & 73 & 0.95 & va & 67.5 & 24.7 & 17.5 & 2.9 & va & 10.1 & 29.6 & 10.4 & 18.1 & 3.3 \\
\hline 170 & 90 & 0.14 & 71 & 81 & 0.88 & va & 72.1 & 29.0 & 19.2 & 3.9 & va & 6.4 & 29.7 & 12.5 & 20.2 & 4.0 \\
\hline 332 & 70 & 0.06 & 55 & 68 & 0.81 & $\mathrm{~s}$ & 47.1 & 13.3 & - & - & $\mathrm{s}$ & 9.5 & 39.4 & 11.0 & - & - \\
\hline
\end{tabular}

$\mathrm{R}_{\mathrm{h}}$ : hydrodynamic radius

$\mathrm{R}_{\mathrm{g}}$ : radius of gyration

$R_{g} / R_{h}$ : ratio of $R_{g}$ over $R_{h}$

$\mathrm{m}$ : morphology observed by cryo-TEM and model chosen for SANS data fitting: $\mathrm{s}$ for sphere, $v$ for vesicle and va for vesicular aggregate

$\mathrm{R}$ : radius measured on cryo-TEM images and radius estimated with SANS data fitting: s) core radius, $\mathrm{v}$ and va) external radius (radius underestimated compared to DLS due to low contrast of PEG for both cryo-TEM and SANS)

$\delta$ : hydrophobic membrane thickness measured on cryo-TEM images and estimated with SANS data fitting

$\mathrm{SD}_{\mathrm{R}}$ and $\mathrm{SD}_{\delta}$ : standard deviations respectively on $\mathrm{R}$ and $\delta$ from cryo-TEM images and SANS data fitting

$\varphi$ : volume fraction: PTMC concentration in particles

The vesicles hydrophobic membrane thickness was plotted as function of the hydrophobic block molar mass (Figure 4). A typical scaling law with a power-dependency was determined with both SANS and cryo-TEM data: $\delta_{S A N S} \propto{\overline{M_{n}}}^{0.56}$ (Figure 4A) and $\delta_{\text {cryo-TEM }} \propto{\overline{M_{n}}}^{0.46}$ (Figure 4B, 4C). This scaling law can be explained considering that a polymer chain in a $\theta$ solvent has a radius of gyration proportional to its molar mass power $0.5\left(R_{g} \propto{\overline{M_{n}}}^{0.5}\right){ }^{50}$ The 
exponent for $\mathrm{PEG}_{45}-b-\mathrm{PTMC}_{\mathrm{n}}$ block copolymers found to be slightly above 0.5 shows that the polymer chains might be slightly stretched in the membrane due to the segregation between PEG and PTMC domains at the vesicle membrane interface. The establishment of such scaling law is important to predict which PTMC block molar mass is needed to obtain a specific hydrophobic membrane thickness, while keeping the $f_{\mathrm{PEG}}$ close to $17 \%$ in order to guarantee the formation of unilamellar vesicles using the manual nanoprecipitation protocol.
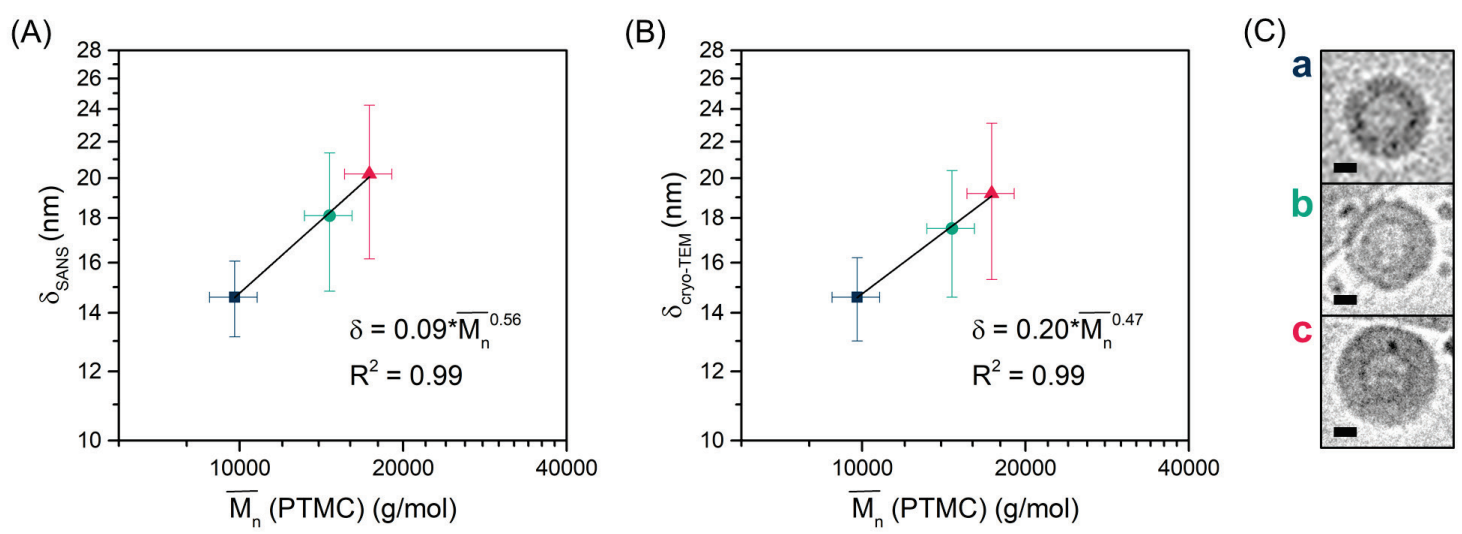

Figure 4. Hydrophobic membrane thickness $(\delta)$ of vesicular objects as a function of the hydrophobic block molar mass $\left(\bar{M}_{n}(\mathrm{PTMC})\right)$ for three $\mathrm{PEG}_{45}-b-\mathrm{PTMC}_{\mathrm{n}}$ copolymers with $\mathrm{n}=$ 96 (blue), 144 (green), 170 (red). Membrane thicknesses were: A) estimated by fitting SANS data $\left(\delta_{S A N S}\right)$ and B) measured on cryo-TEM images $\left(\delta_{\text {cryo-TEM }}\right)$. Fits show a power dependency of $\delta$ with $\bar{M}_{n}$ by an exponent of 0.56 for $\delta_{\text {SANS }}(\mathrm{A})$ and 0.47 for $\delta_{\text {cryo-TEM }}(\mathrm{B})$. C) Cryo-TEM images focusing on one polymersome of mNP96 (a, blue), mNP144 (b, green) and mNP170 (c, red). Scale bar: $20 \mathrm{~nm}$.

The results of this self-assembly study using the same formulation protocol showed how the hydrophilic fraction $\mathrm{f}_{\mathrm{PEG}}$ of $\mathrm{PEG}_{45}-b-\mathrm{PTMC}_{\mathrm{n}}$ is dictating the nanoparticles morphology. 
In a second time, we studied the influence of the nanoprecipitation process, including the use of a microfluidic device, on the size and morphology of the self-assembled nanoparticles, focusing on $\mathrm{PEG}_{45}-b-\mathrm{PTMC}_{96}$ block copolymer.

\section{Influence of the nanoprecipitation process}

Manual nanoprecipitation of $\mathrm{PEG}_{45}-b$ - $\mathrm{PTMC}_{96}$ was first performed by a reverse addition (mNP-ra96) of the copolymer solution in DMSO into water and subsequent dialysis against water. DLS $90^{\circ}$ curve showed smaller objects for mNP-ra96 than for mNP96 with $\mathrm{R}_{\mathrm{h}} \approx 30 \mathrm{~nm}$ versus $55 \mathrm{~nm}$ (Figure 5).

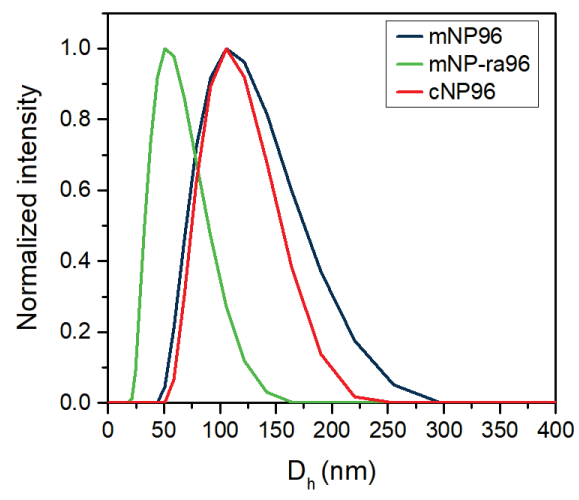

Figure 5. DLS $90^{\circ}$ curves of the different $\mathrm{PEG}_{45}-b-\mathrm{PTMC}_{96}$ nanoparticles obtained by different processes: manual nanoprecipitation upon addition of water in the copolymer solution (mNP96, blue) or upon reverse addition (mNP-ra96, green) and by controlled nanoprecipitation using microfluidics (cNP96, red).

Combined characteristics from MALS, cryo-TEM and SANS (Figure 6, Table 3) confirmed for mNP-ra96 a micellar structure of the objects with a core size close to $11 \mathrm{~nm}$. This change in morphology correlated to a modification in the order of solvent addition can be expected since it may increase the rate at which the copolymer is precipitated, the overall system being thermodynamically out of equilibrium (in a "frozen" state). 
(A)

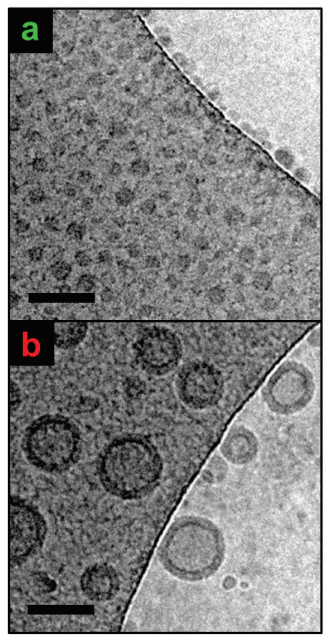

(B)

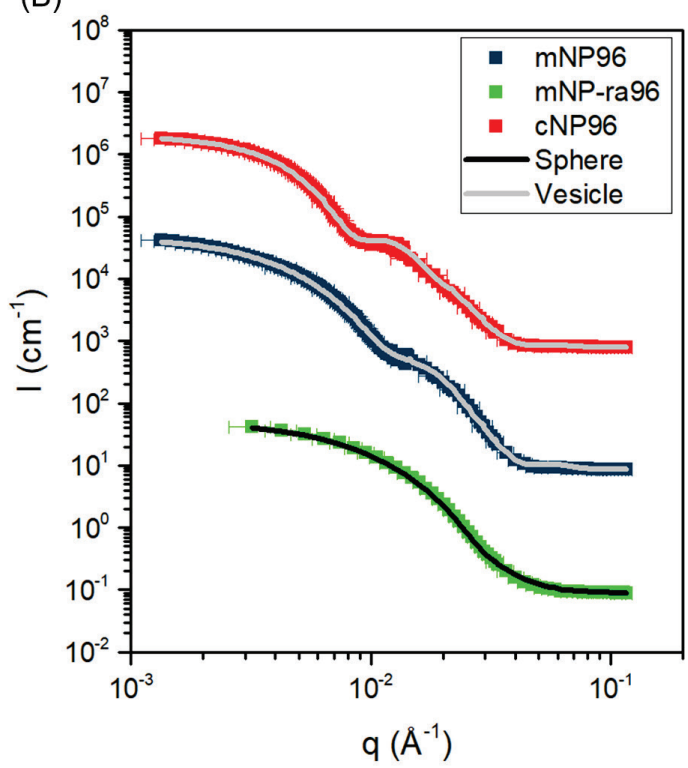

Figure 6. Cryo-TEM images (A) and SANS curves (B) of the different $\mathrm{PEG}_{45}-b-\mathrm{PTMC}_{96}$ nanoparticles obtained by different processes: manual nanoprecipitation upon addition of water in the copolymer solution (mNP96, blue) or upon reverse addition (mNP-ra96, green, a) and by controlled nanoprecipitation using microfluidics (cNP96, red, b). A) Scale bar: 100 nm. For comparison, cryo-TEM image of mNP96 can be found in Figure 3. B) Neutron scattering curves were fitted with theoratical plots for different morphology models: sphere (black line) or unilamellar vesicle (grey line) with $10^{2} \mathrm{~cm}^{-1}$ of offset between curves. Curves of mNP96 (blue) is reminded for easier comparison. 
Table 3. DLS $90^{\circ}$, MALS, cryo-TEM and SANS data of the different $\mathrm{PEG}_{45}-b-\mathrm{PTMC}_{96}$ nanoparticles obtained by different processes: manual nanoprecipitation upon addition of water in the copolymer solution (mNP96) or upon reverse addition (mNP-ra96) and by controlled nanoprecipitation using microfluidics (cNP96).

\begin{tabular}{|c|c|c|c|c|c|c|c|c|c|c|c|c|c|c|c|c|}
\hline \multirow[b]{2}{*}{ Sample } & \multicolumn{2}{|c|}{ DLS 90 } & \multicolumn{3}{|c|}{ MALS } & \multicolumn{5}{|c|}{ Cryo-TEM } & \multicolumn{6}{|c|}{ SANS } \\
\hline & $\begin{array}{l}\mathrm{R}_{\mathrm{h}} \\
(\mathrm{nm})\end{array}$ & PDI & $\begin{array}{l}\mathrm{R}_{\mathrm{g}} \\
(\mathrm{nm})\end{array}$ & $\begin{array}{c}\mathrm{R}_{\mathrm{h}} \\
(\mathrm{nm})\end{array}$ & $\mathrm{R}_{\mathrm{g}} / \mathrm{R}_{\mathrm{h}}$ & $\mathrm{m}$ & $\begin{array}{c}\mathrm{R} \\
(\mathrm{nm})\end{array}$ & $\begin{array}{l}\mathrm{SD}_{\mathrm{R}} \\
(\mathrm{nm})\end{array}$ & $\begin{array}{c}\delta \\
(\mathrm{nm})\end{array}$ & $\begin{array}{l}\mathrm{SD}_{\delta} \\
(\mathrm{nm})\end{array}$ & $\mathrm{m}$ & $\begin{array}{c}\varphi \\
\left(10^{-4} \mathrm{~g} / \mathrm{mL}\right)\end{array}$ & $\begin{array}{c}\mathrm{R} \\
(\mathrm{nm})\end{array}$ & $\begin{array}{l}\mathrm{SD}_{\mathrm{R}} \\
(\mathrm{nm})\end{array}$ & $\begin{array}{c}\delta \\
(\mathrm{nm})\end{array}$ & $\begin{array}{l}\mathrm{SD}_{\delta} \\
(\mathrm{nm})\end{array}$ \\
\hline mNP96 & 55 & 0.13 & 53 & 51 & 1.04 & $\mathrm{v}$ & 37.3 & 15.0 & 14.6 & 1.6 & $\mathrm{v}$ & 8.8 & 15.5 & 5.4 & 14.6 & 1.5 \\
\hline mNP-ra96 & 30 & 0.17 & 34 & 28 & 1.21 & $\mathrm{~s}$ & 11.3 & 4.6 & - & - & $\mathrm{s}$ & 7.2 & 11.3 & 3.5 & - & - \\
\hline cNP96 & 55 & 0.04 & 49 & 51 & 0.96 & $\mathrm{v}$ & 40.6 & 7.4 & 14.7 & 1.6 & $\mathrm{v}$ & 3.4 & 25.0 & 6.5 & 14.2 & 1.8 \\
\hline
\end{tabular}

$\mathrm{R}_{\mathrm{h}}$ : hydrodynamic radius

$\mathrm{R}_{\mathrm{g}}$ : radius of gyration

$R_{g} / R_{h}$ : ratio of $R_{g}$ over $R_{h}$

m: morphology observed by cryo-TEM and model chosen for SANS data fitting: $\mathrm{s}$ for sphere and $\mathrm{v}$ for vesicle

$\mathrm{R}$ : radius measured on cryo-TEM images and radius estimated with SANS data fitting: s) core radius and v) external radius (radius underestimated compared to DLS due to low contrast of PEG for both cryo-TEM and SANS)

$\delta$ : hydrophobic membrane thickness measured on cryo-TEM images and estimated with SANS data fitting

$\mathrm{SD}_{\mathrm{R}}$ and $\mathrm{SD}_{\delta}$ : standard deviations respectively on $\mathrm{R}$ and $\delta$ from cryo-TEM images and SANS data fitting

$\varphi:$ volume fraction: PTMC concentration in particles

The third preparation process used was controlled nanoprecipitation (cNP), carried out using a microfluidic system depicted in Figure S7. A screening of different conditions with such a versatile system was performed again with $\mathrm{PEG}_{45}-b-\mathrm{PTMC}_{96}$. Different flow rate, water content and initial copolymer concentration were tested in three different microfluidic set-ups (Figure S8). Nanoparticles obtained from the $\mathrm{H}_{2} \mathrm{O} /$ DMSO mixture (before removal of DMSO by dialysis) were characterized by DLS $90^{\circ}$ with the adequate solvent viscosity. 
Results indicated in Table S3 revealed that nanoparticles' size was increased upon an increase of the copolymer concentration in the final $\mathrm{H}_{2} \mathrm{O} / \mathrm{DMSO}$ mixture. This trend was observed when the water content was decreased while keeping the initial copolymer concentration constant. The same trend was also found when the initial copolymer concentration was increased while keeping the water content constant. Secondly, the decrease of the total flow rate gave slightly bigger objects for water contents of 50 and $70 \mathrm{vol} \%$. In addition, for $30 \mathrm{vol} \%$, no real impact on the size was observed. Finally, a negligible effect was observed on the objects size formed with the three different set-ups that were tested.

With all the different conditions carried out, we managed to control the objects size with $R_{h}$ between 22 and $85 \mathrm{~nm}$ and a PDI repeatedly lower than 0.1 . Only size is mentioned here since no other characterization than DLS $90^{\circ}$ was performed to determine the objects morphology. However, since mNP-ra96 was demonstrated to form micelles of $\mathrm{R}_{\mathrm{h}} \approx 30 \mathrm{~nm}$ with a fast mixing process, one can expect micelles for the smaller objects formed by microfluidics in rather similar conditions, and vesicles for objects with $R_{h} \geq 50 \mathrm{~nm}$ since mNP96 was shown to form vesicles when close to equilibrium. As such, one specific sample giving $R_{h}=58 \mathrm{~nm}$ before dialysis (cNP96) was studied thoroughly to confirm the vesicular structure. The conditions used in the microfluidics system were as follows: a flow rate of $100 \mu \mathrm{L} / \mathrm{min}$ for $\mathrm{H}_{2} \mathrm{O}, 233 \mu \mathrm{L} / \mathrm{min}$ for the copolymer solution in DMSO at $1 \mathrm{~g} / \mathrm{L}$, meaning a water content of 30 vol\%. First, DLS $90^{\circ}$ was done after dialysis (Figure 5) and showed $\mathrm{R}_{\mathrm{h}}=55 \mathrm{~nm}$ with PDI $=0.04$ (Table 3 ) which was much lower than the one of mNP96 with 0.13 . Further data from MALS, cryo-TEM and SANS confirmed a vesicle morphology of cNP96 (Figure 6, Table 3) with the same membrane thickness $(\delta \approx 14.6 \mathrm{~nm})$ as for mNP96 vesicles, since it is an intrinsic characteristic of the $\mathrm{PEG}_{45}-b$ - $\mathrm{PTMC}_{96}$ copolymer.

However, for cNP96, smaller size dispersity was observed by cryo-TEM and the oscillation characteristic of the bilayer thickness observed by SANS was well marked, confirming an 
overall well-defined size of vesicles. To conclude, microfluidics was found to be a successful technique with this particular condition to obtain more monodisperse vesicles than the manual nanoprecipitation procedure.

Controlled nanoprecipitation (cNP) with the same microfluidic conditions was then applied for all the other block copolymers of the series, and the obtained nanoparticles were characterized by DLS $90^{\circ}$, MALS and cryo-TEM (Figure 7f-j, Table S4). cNP38 gave micelles with the same core radius than for mNP38 of $8 \mathrm{~nm}$ but aggregates were obtained too, leading to a poor PDI of 0.7 . cNP144 and 170 generated a mixture of vesicles of $40 \mathrm{~nm}$ and spheres of 20 to $30 \mathrm{~nm}$ in radius, as determined by cryo-TEM. Hence, vesicular aggregates were avoided via microfluidics but the hydrophilic weight fraction of these two block copolymers are probably too low to find a good condition to obtain exclusively a vesicular shape. Values of membrane thicknesses were a bit higher than the ones obtained for mNP144 and 170 (Table 2) but still within the standard deviations. Finally, cNP332 produced spheres of $\mathrm{R}_{\mathrm{h}} \approx 50 \mathrm{~nm}$, smaller than for mNP332 with a good PDI of 0.14 . These results showed that applying the same microfluidic condition on four different block copolymers of our series with $\mathrm{f}_{\mathrm{PEG}} \leq 17 \%\left(\mathrm{PEG}_{45}-b-\mathrm{PTMC}_{\mathrm{n}} \mathrm{n}=96,144,170,332\right)$ confirmed the power of microfluidics to control nanoparticles size with low dispersity for morphologies between vesicles and spheres. An optimization of the different microfluidics conditions could be investigated in order to perfect the resulting nanoparticles, especially on $\mathrm{PEG}_{45}-b-\mathrm{PTMC}_{38}$ with $\mathrm{f}_{\mathrm{PEG}} \approx 34 \%$ in order to obtain monodisperse micelles.

\section{CONCLUSIONS}

In this work, the synthesis by ROP of five $\mathrm{PEG}_{45}-b-\mathrm{PTMC}_{\mathrm{n}}$ block copolymers was performed to obtain different hydrophilic weight fraction $f_{P E G}$ between $34 \%$ and $6 \%$ by 
changing the PTMC chain length $(\mathrm{n}=38,96,140,170,332)$. These copolymers are of particular interest for the design of biomaterials due to the known biocompatibility of PEG and the low systemic toxicity of PTMC. ${ }^{35}$ In addition, the PTMC block has also been interestingly reported to be biodegradable upon enzymatic hydrolysis. ${ }^{37,38,22}$ This series was self-assembled using different processes to form nanoparticles with different sizes and morphologies (Figure 7).

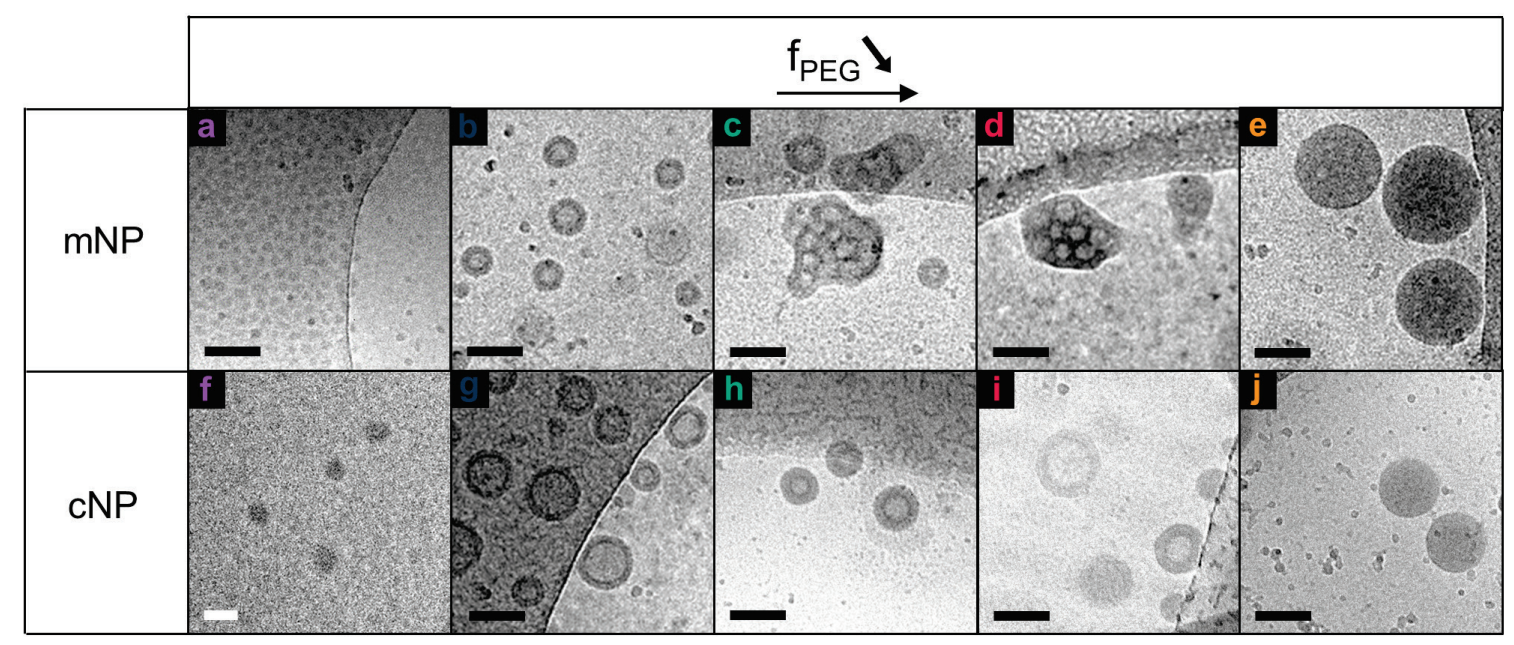

Figure 7. Summary of cryo-TEM images of the different nanoparticles obtained by manual nanoprecipitation (mNP, a-e) and controlled nanoprecipitation (cNP, f-j) using the series of $\mathrm{PEG}_{45}-b-\mathrm{PTMC}_{\mathrm{n}}$ diblock copolymers with $\mathrm{n}=38$ (purple, a/f), 96 (blue, b/g), 144 (green, c/h), 170 (red, d/i), 332 (orange, e/j). Black scale bar: $100 \mathrm{~nm}$; white scale bar (f): $20 \mathrm{~nm}$.

First, by applying the same manual nanoprecipitation protocol for all copolymers, different morphologies were obtained according to $\mathrm{f}_{\mathrm{PEG}}$ : micelles for $\mathrm{f}_{\mathrm{PEG}} \approx 34 \%$, vesicles for $17 \%<$ $\mathrm{f}_{\mathrm{PEG}}<10 \%$ and spheres for $\mathrm{f}_{\mathrm{PEG}} \approx 6 \%$ (Figure $7, \mathrm{mNP}$ ). Then, by controlled nanoprecipitation using a microfluidic system, it was possible to control nanoparticles size while keeping the same morphologies (Figure 7, cNP), indicating that the shape of the self-assembled structures is truly dictated by the macromolecular parameters $\left(f_{\mathrm{PEG}}\right)$, when formed at equilibrium. 
Indeed, when mixing rate is fast enough to be thermodynamically out of equilibrium and in a "frozen" state, other morphologies can also be obtained. This was illustrated by the observation of vesicles formed by manual nanoprecipitation of $\mathrm{PEG}_{45}-b$-PTMC 96 upon addition of water in the copolymer solution while "frozen" micelles were obtained when the addition was performed reversely, leading to a rapid nanoprecipitation process.

Furthermore, a microfluidic study on the best copolymer candidate to form vesicles, $\mathrm{PEG}_{45^{-}}$ $b$-PTMC ${ }_{96}\left(f_{\mathrm{PEG}} \approx 17 \%\right)$, showed that vesicles size can be tuned and controlled by changing different parameters such as flow rates, water content and copolymer concentration. One condition was found to match the same vesicle size as the one obtained by manual nanoprecipitation $\left(\mathrm{D}_{\mathrm{h}} \approx 100 \mathrm{~nm}\right)$ with excellent monodispersity $(\mathrm{PDI}<0.1)$. Vesicles had the same membrane thickness $(\delta \approx 14.6 \mathrm{~nm})$, illustrating that $\delta$ is only imposed by the copolymer and not dependent on the formulation process.

Finally, a scaling law was drawn: $\delta \propto{\overline{M_{n}}}^{0.56}$, the hydrophobic membrane thickness $\delta$ is proportional to the molar mass of the hydrophobic block $\overline{M_{n}}$ to a power 0.56 . This simple but influential law will provide anyone working on similar copolymers to predict the membrane thickness of vesicles and engineer the appropriate copolymer, providing that $f_{\text {PEG }}$ remains close to $17 \%$ to maintain a vesicular structure.

As a general outlook, we now have all the tools needed to form PEG- $b$-PTMC vesicles with different membrane thicknesses and PEG lengths in order to tune certain physicochemical membrane properties (stability, permeability, fluidity...) which are critical parameters for future applications in biomaterial science and drug delivery. In future work, this will be especially interesting to study the effect of PEG length on colloidal stability and stealth properties, and the effect of the polymersome membrane thickness on mechanical and diffusion properties. In addition, the ability to fine-tune the polymersome size using a microfluidic assisted nanoprecipitation method, with very low dispersity and high 
repeatability is crucial for clinical and industrial development of nanoparticles, especially polymersomes.

\section{ASSOCIATED CONTENT}

Supporting Information is available. ${ }^{1} \mathrm{H}$ NMR spectra, SEC chromatograms, TGA thermograms, additional DSC, DLS, MALS, cryo-TEM data and scheme of the microfluidic system.

\section{AUTHOR INFORMATION}

Corresponding Author. *Tel: +33 540006603 Fax: +33 5400084 87. Email: lecommandoux@enscbp.fr

Author Contributions. This manuscript was written through contributions of all authors. These authors \$ contributed equally. All authors have given approval to the final version of the manuscript.

\section{ORCID.}

Coralie Lebleu: 0000-0003-1843-8599

Laura Rodrigues: 0000-0001-6158-6314

Elisabeth Garanger: 0000-0001-9130-8286

Sébastien Lecommandoux: 0000-0003-0465-8603

\section{CONFLICTS OF INTEREST}

The authors declare no conflicts of interest. 


\section{ACKNOWLEDGEMENTS}

This work was sponsored by La Ligue Nationale Contre le Cancer through a $\mathrm{PhD}$ grant awarded to Laura Rodrigues. Campus-B project, CNRS, Univ. Bordeaux, Bordeaux INP and the Région Nouvelle Aquitaine are also acknowledged. This work benefited from the use of the SasView application, originally developed under NSF Award DMR-0520547. SasView also contains code developed with funding from the EU Horizon 2020 program under the SINE2020 project Grant No 654000. 


\section{REFERENCES}

(1) Nicolas, J.; Mura, S.; Brambilla, D.; Mackiewicz, N.; Couvreur, P. Design, Functionalization Strategies and Biomedical Applications of Targeted Biodegradable/Biocompatible Polymer-Based Nanocarriers for Drug Delivery. Chem. Soc. Rev. 2013, 42 (3), 1147-1235. https://doi.org/10.1039/C2CS35265F.

(2) Chan, J. M.; Valencia, P. M.; Zhang, L.; Langer, R.; Farokhzad, O. C. Polymeric Nanoparticles for Drug Delivery. In Cancer Nanotechnology: Methods and Protocols; Grobmyer, S. R., Moudgil, B. M., Eds.; Methods in Molecular Biology; Humana Press: Totowa, NJ, 2010; pp 163-175. https://doi.org/10.1007/978-1-60761-609-2_11.

(3) Anselmo, A. C.; Mitragotri, S. Nanoparticles in the Clinic. Bioeng. Transl. Med. 2016, 1 (1), 10-29. https://doi.org/10.1002/btm2.10003.

(4) Anselmo, A. C.; Prabhakarpandian, B.; Pant, K.; Mitragotri, S. Clinical and Commercial Translation of Advanced Polymeric Nanoparticle Systems: Opportunities and Material Challenges. Transl. Mater. Res. 2017, 4 (1), 014001. https://doi.org/10.1088/2053-1613/aa5468.

(5) Discher, D. E.; Eisenberg, A. Polymer Vesicles. Science 2002, 297 (5583), 967-973. https://doi.org/10.1126/science.1074972.

(6) Discher, B. M.; Won, Y.-Y.; Ege, D. S.; Lee, J. C.-M.; Bates, F. S.; Discher, D. E.; Hammer, D. A. Polymersomes: Tough Vesicles Made from Diblock Copolymers. Science 1999, 284 (5417), 1143-1146. https://doi.org/10.1126/science.284.5417.1143.

(7) Blanazs, A.; Armes, S. P.; Ryan, A. J. Self-Assembled Block Copolymer Aggregates: From Micelles to Vesicles and Their Biological Applications. Macromol. Rapid Commun. 2009, 30 (4-5), 267-277. https://doi.org/10.1002/marc.200800713.

(8) Levine, D. H.; Ghoroghchian, P. P.; Freudenberg, J.; Zhang, G.; Therien, M. J.; Greene, M. I.; Hammer, D. A.; Murali, R. Polymersomes: A New Multi-Functional Tool for Cancer Diagnosis and Therapy. Methods 2008, 46 (1), 25-32. https://doi.org/10.1016/j.ymeth.2008.05.006.

(9) Brinkhuis, R. P.; Rutjes, F. P. J. T.; van Hest, J. C. M. Polymeric Vesicles in Biomedical Applications. Polym. Chem. 2011, 2 (7), 1449-1462. https://doi.org/10.1039/C1PY00061F.

(10) De Oliveira, H.; Thevenot, J.; Lecommandoux, S. Smart Polymersomes for Therapy and Diagnosis: Fast Progress toward Multifunctional Biomimetic Nanomedicines. WIRES Nanomed. Nanobiotechnol. 2012, 4 (5), 525-546. https://doi.org/10.1002/wnan.1183.

(11) Lee, J. S.; Feijen, J. Polymersomes for Drug Delivery: Design, Formation and Characterization. J. Control. Release 2012, 161 (2), 473-483. https://doi.org/10.1016/j.jconrel.2011.10.005.

(12) Guan, L.; Rizzello, L.; Battaglia, G. Polymersomes and Their Applications in Cancer Delivery and Therapy. Nanomedicine 2015, 10 (17), 2757-2780. https://doi.org/10.2217/nnm.15.110.

(13) Siepmann, J.; Faham, A.; Clas, S.-D.; Boyd, B. J.; Jannin, V.; Bernkop-Schnürch, A.; Zhao, H.; Lecommandoux, S.; Evans, J. C.; Allen, C.; et al. Lipids and Polymers in Pharmaceutical Technology: Lifelong Companions. Int. J. Pharm. 2019, 558, 128-142. https://doi.org/10.1016/j.ijpharm.2018.12.080.

(14) Bermudez, H.; Brannan, A. K.; Hammer, D. A.; Bates, F. S.; Discher, D. E. Molecular Weight Dependence of Polymersome Membrane Structure, Elasticity, and Stability. Macromolecules 2002, 35 (21), 8203-8208. https://doi.org/10.1021/ma0206691. 
(15) Bermudez, H.; Hammer, D. A.; Discher, D. E. Effect of Bilayer Thickness on Membrane Bending Rigidity. Langmuir 2004, 20 (3), 540-543. https://doi.org/10.1021/la035497f.

(16) Discher, D. E.; Ahmed, F. Polymersomes. Annu. Rev. Biomed. Eng. 2006, 8 (1), 323341. https://doi.org/10.1146/annurev.bioeng.8.061505.095838.

(17) Le Meins, J.-F.; Sandre, O.; Lecommandoux, S. Recent Trends in the Tuning of Polymersomes' Membrane Properties. Eur. Phys. J. E 2011, 34 (2), 14. https://doi.org/10.1140/epje/i2011-11014-y.

(18) Rideau, E.; Dimova, R.; Schwille, P.; Wurm, F. R.; Landfester, K. Liposomes and Polymersomes: A Comparative Review towards Cell Mimicking. Chem. Soc. Rev. 2018, 47 (23), 8572-8610. https://doi.org/10.1039/C8CS00162F.

(19) Varlas, S.; Foster, J. C.; Georgiou, P. G.; Keogh, R.; Husband, J. T.; Williams, D. S.; O'Reilly, R. K. Tuning the Membrane Permeability of Polymersome Nanoreactors Developed by Aqueous Emulsion Polymerization-Induced Self-Assembly. Nanoscale 2019, 11 (26), 12643-12654. https://doi.org/10.1039/C9NR02507C.

(20) Wang, X.; Liu, G.; Hu, J.; Zhang, G.; Liu, S. Concurrent Block Copolymer Polymersome Stabilization and Bilayer Permeabilization by Stimuli-Regulated "Traceless" Crosslinking. Angew. Chem. Int. Ed. 2014, 53 (12), 3138-3142. https://doi.org/10.1002/anie.201310589.

(21) Wang, X.; Hu, J.; Liu, G.; Tian, J.; Wang, H.; Gong, M.; Liu, S. Reversibly Switching Bilayer Permeability and Release Modules of Photochromic Polymersomes Stabilized by Cooperative Noncovalent Interactions. J. Am. Chem. Soc. 2015, 137 (48), 1526215275. https://doi.org/10.1021/jacs.5b10127.

(22) Sanson, C.; Schatz, C.; Le Meins, J.-F.; Brûlet, A.; Soum, A.; Lecommandoux, S. Biocompatible and Biodegradable Poly(Trimethylene Carbonate)-b-Poly(1-Glutamic Acid) Polymersomes: Size Control and Stability. Langmuir 2010, 26 (4), 2751-2760. https://doi.org/10.1021/la902786t.

(23) Dionzou, M.; Morère, A.; Roux, C.; Lonetti, B.; Marty, J.-D.; Mingotaud, C.; Joseph, P.; Goudounèche, D.; Payré, B.; Léonetti, M.; et al. Comparison of Methods for the Fabrication and the Characterization of Polymer Self-Assemblies: What Are the Important Parameters? Soft Matter 2016, 12 (7), 2166-2176. https://doi.org/10.1039/C5SM01863C.

(24) So, S.; Lodge, T. P. Size Control and Fractionation of Ionic Liquid Filled Polymersomes with Glassy and Rubbery Bilayer Membranes. Langmuir 2016, 32 (19), 4959-4968. https://doi.org/10.1021/acs.langmuir.6b00946.

(25) Brown, L.; McArthur, S. L.; Wright, P. C.; Lewis, A.; Battaglia, G. Polymersome Production on a Microfluidic Platform Using PH Sensitive Block Copolymers. Lab Chip 2010, 10 (15), 1922-1928. https://doi.org/10.1039/C004036C.

(26) Thiermann, R.; Mueller, W.; Montesinos-Castellanos, A.; Metzke, D.; Löb, P.; Hessel, V.; Maskos, M. Size Controlled Polymersomes by Continuous Self-Assembly in Micromixers. Polymer 2012, 53 (11), 2205-2210. https://doi.org/10.1016/j.polymer.2012.03.058.

(27) Bleul, R.; Thiermann, R.; Maskos, M. Techniques To Control Polymersome Size. $\begin{array}{lllll}\text { Macromolecules } & \mathbf{2 0 1 5}, & 48 & \text { 7396-7409. }\end{array}$ https://doi.org/10.1021/acs.macromol.5b01500.

(28) Albuquerque, L. J. C.; Sincari, V.; Ja?ger, A.; Konefa?, R.; Pa?nek, J.; C?ernoch, P.; Pavlova, E.; S?te?pa?nek, P.; Giacomelli, F. C.; Ja?ger, E. Microfluidic-Assisted Engineering of Quasi-Monodisperse PH-Responsive Polymersomes toward Advanced Platforms for the Intracellular Delivery of Hydrophilic Therapeutics. Langmuir 2019, 35 (25), 8363-8372. https://doi.org/10.1021/acs.langmuir.9b01009. 
(29) Ahmed, F.; Pakunlu, R. I.; Brannan, A.; Bates, F.; Minko, T.; Discher, D. E. Biodegradable Polymersomes Loaded with Both Paclitaxel and Doxorubicin Permeate and Shrink Tumors, Inducing Apoptosis in Proportion to Accumulated Drug. $J$. Control. Release 2006, 116 (2), 150-158. https://doi.org/10.1016/j.jconrel.2006.07.012.

(30) Onaca, O.; Enea, R.; Hughes, D. W.; Meier, W. Stimuli-Responsive Polymersomes as Nanocarriers for Drug and Gene Delivery. Macromol. Biosci. 2009, 9 (2), 129-139. https://doi.org/10.1002/mabi.200800248.

(31) Meng, F.; Zhong, Z.; Feijen, J. Stimuli-Responsive Polymersomes for Programmed Drug Delivery. Biomacromolecules 2009, $10 \quad$ (2), 197-209. https://doi.org/10.1021/bm801127d.

(32) Hu, X.; Zhang, Y.; Xie, Z.; Jing, X.; Bellotti, A.; Gu, Z. Stimuli-Responsive Polymersomes for Biomedical Applications. Biomacromolecules 2017, 18 (3), 649673. https://doi.org/10.1021/acs.biomac.6b01704.

(33) Rabanel, J.-M.; Hildgen, P.; Banquy, X. Assessment of PEG on Polymeric Particles Surface, a Key Step in Drug Carrier Translation. J. Control. Release 2014, 185 (Supplement C), 71-87. https://doi.org/10.1016/j.jconrel.2014.04.017.

(34) Photos, P. J.; Bacakova, L.; Discher, B.; Bates, F. S.; Discher, D. E. Polymer Vesicles in Vivo: Correlations with PEG Molecular Weight. J. Control. Release 2003, 90 (3), 323-334. https://doi.org/10.1016/S0168-3659(03)00201-3.

(35) Nair, L. S.; Laurencin, C. T. Biodegradable Polymers as Biomaterials. Progress in $\begin{array}{lllll}\text { Polymer Science } & \mathbf{2 0 0 7}, & 32 & \text { (8-9), } & \text { 762-798. }\end{array}$ https://doi.org/10.1016/j.progpolymsci.2007.05.017.

(36) Ahmed, F.; Discher, D. E. Self-Porating Polymersomes of PEG-PLA and PEG-PCL: Hydrolysis-Triggered Controlled Release Vesicles. J. Control. Release 2004, 96 (1), 37-53. https://doi.org/10.1016/j.jconrel.2003.12.021.

(37) Albertsson, A.-C.; Eklund, M. Influence of Molecular Structure on the Degradation Mechanism of Degradable Polymers: In Vitro Degradation of Poly(Trimethylene Carbonate), Poly(Trimethylene Carbonate-Co-Caprolactone), and Poly(Adipic Anhydride). J. Appl. Polym. Sci. 1995, 57 (1), 87-103. https://doi.org/10.1002/app.1995.070570109.

(38) Zhang, Z.; Kuijer, R.; Bulstra, S. K.; Grijpma, D. W.; Feijen, J. The in Vivo and in Vitro Degradation Behavior of Poly(Trimethylene Carbonate). Biomaterials 2006, 27 (9), 1741-1748. https://doi.org/10.1016/j.biomaterials.2005.09.017.

(39) Sanson, C.; Meins, J.-F. L.; Schatz, C.; Soum, A.; Lecommandoux, S. Temperature Responsive Poly(Trimethylene Carbonate)-Block-Poly(L-Glutamic Acid) Copolymer: Polymersomes Fusion and Fission. Soft Matter 2010, 6 (8), 1722-1730. https://doi.org/10.1039/B924617G.

(40) Cao, S.; Abdelmohsen, L. K. E. A.; Shao, J.; van den Dikkenberg, J.; Mastrobattista, E.; Williams, D. S.; van Hest, J. C. M. PH-Induced Transformation of Biodegradable Multilamellar Nanovectors for Enhanced Tumor Penetration. ACS Macro Lett. 2018, 7 (11), 1394-1399. https://doi.org/10.1021/acsmacrolett.8b00807.

(41) Ridolfo, R.; Ede, B. C.; Diamanti, P.; White, P. B.; Perriman, A. W.; Hest, J. C. M. van; Blair, A.; Williams, D. S. Biodegradable, Drug-Loaded Nanovectors via Direct Hydration as a New Platform for Cancer Therapeutics. Small 2018, 14 (32), 1703774. https://doi.org/10.1002/smll.201703774.

(42) Jiang, X.; Xin, H.; Sha, X.; Gu, J.; Jiang, Y.; Law, K.; Chen, Y.; Chen, L.; Wang, X.; Fang, X. PEGylated Poly(Trimethylene Carbonate) Nanoparticles Loaded with Paclitaxel for the Treatment of Advanced Glioma: In Vitro and in Vivo Evaluation. Int. J. Pharm. 2011, 420 (2), 385-394. https://doi.org/10.1016/j.ijpharm.2011.08.052. 
(43) Meng, F.; Hiemstra, C.; Engbers, G. H. M.; Feijen, J. Biodegradable Polymersomes. Macromolecules 2003, 36 (9), 3004-3006. https://doi.org/10.1021/ma034040+.

(44) Li, S.; Meng, F.; Wang, Z.; Zhong, Y.; Zheng, M.; Liu, H.; Zhong, Z. Biodegradable Polymersomes with an Ionizable Membrane: Facile Preparation, Superior Protein Loading, and Endosomal PH-Responsive Protein Release. Eur. J. Pharm. Biopharm. 2012, 82 (1), 103-111. https://doi.org/10.1016/j.ejpb.2012.05.009.

(45) Drappier, C.; Oliveira, H.; Sandre, O.; Ibarboure, E.; Combet, S.; Garanger, E.; Lecommandoux, S. Self-Assembled Core-Shell Micelles from Peptide-b-Polymer Molecular Chimeras towards Structure-Activity Relationships. Faraday Discuss. 2014, 166 (0), 83-100. https://doi.org/10.1039/C3FD00098B.

(46) Cotton, J.-P. Neutron, X-Ray and Light Scattering: Introduction to an Investigative Tool for Colloidal and Polymeric Systems, North-Holland: Delta Series.; Lindner P., Zemb Th., 1991.

(47) Teixeira, J. Small-Angle Scattering by Fractal Systems. J. Appl. Cryst. 1988, 21 (6), 781-785. https://doi.org/10.1107/S0021889888000263.

(48) Zhu, K. J.; Hendren, R. W.; Jensen, K.; Pitt, C. G. Synthesis, Properties, and Biodegradation of Poly(1,3-Trimethylene Carbonate). Macromolecules 1991, 24 (8), 1736-1740. https://doi.org/10.1021/ma00008a008.

(49) Chécot, F.; Brûlet, A.; Oberdisse, J.; Gnanou, Y.; Mondain-Monval, O.; Lecommandoux, S. Structure of Polypeptide-Based Diblock Copolymers in Solution: Stimuli-Responsive Vesicles and Micelles. Langmuir 2005, 21 (10), 4308-4315. https://doi.org/10.1021/la0468500.

(50) Battaglia, G.; Ryan, A. J. Bilayers and Interdigitation in Block Copolymer Vesicles. J. Am. Chem. Soc. 2005, 127 (24), 8757-8764. https://doi.org/10.1021/ja050742y. 
For Table of Contents Only

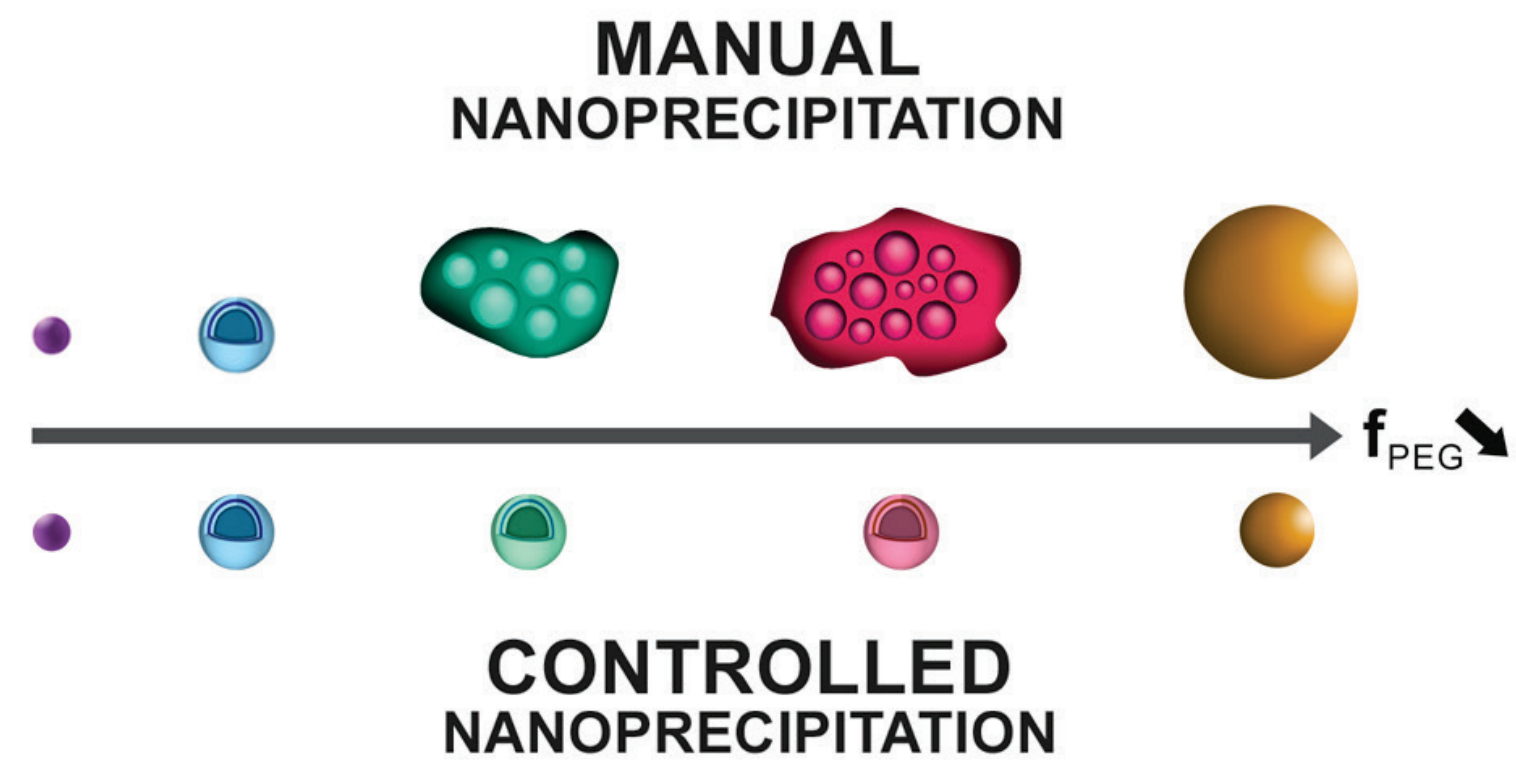

